\title{
Estuarine Exchange Flow Variability in a Seasonal, Segmented Estuary
}

\author{
Ted Conroy AND DAvid A. Sutherland \\ University of Oregon, Eugene, Oregon \\ DAVID K. RALSTON \\ Woods Hole Oceanographic Institution, Woods Hole, Massachusetts
}

(Manuscript received 6 May 2019, in final form 4 December 2019)

\begin{abstract}
Small estuaries in Mediterranean climates display pronounced salinity variability at seasonal and event time scales. Here, we use a hydrodynamic model of the Coos Estuary, Oregon, to examine the seasonal variability of the salinity dynamics and estuarine exchange flow. The exchange flow is primarily driven by tidal processes, varying with the spring-neap cycle rather than discharge or the salinity gradient. The salinity distribution is rarely in equilibrium with discharge conditions because during the wet season the response time scale is longer than discharge events, while during low flow it is longer than the entire dry season. Consequently, the salt field is rarely fully adjusted to the forcing and common power-law relations between the salinity intrusion and discharge do not apply. Further complicating the salinity dynamics is the estuarine geometry that consists of multiple branching channel segments with distinct freshwater sources. These channel segments act as subestuaries that import both higher- and lower-salinity water and export intermediate salinities. Throughout the estuary, tidal dispersion scales with tidal velocity squared, and likely includes jet-sink flow at the mouth, lateral shear dispersion, and tidal trapping in branching channel segments inside the estuary. While the estuarine inflow is strongly correlated with tidal amplitude, the outflow, stratification, and total mixing in the estuary are dependent on the seasonal variation in river discharge, which is similar to estuaries that are dominated by subtidal exchange flow.
\end{abstract}

\section{Introduction}

Estuaries are subject to variability in freshwater input on discharge event, seasonal, and multiyear time scales, which changes the along-estuary salinity distribution and resulting baroclinic pressure gradient. Classic estuarine theory relates the estuarine exchange flow to the strength of the baroclinic pressure gradient, which is balanced by vertical stress divergence (i.e., gravitational circulation; Pritchard 1956; Hansen and Rattray 1965; MacCready 2007). In that framework, variations in the baroclinic pressure gradient associated with seasonal river discharge result in changes in the exchange flow. The magnitude of the exchange flow dictates the flushing of an estuary, as it affects the transport of water parcels, nutrients, organisms, and pollutants between an estuary and the coastal ocean (MacCready and Banas 2011; Geyer and MacCready 2014).

Estuaries in Mediterranean climates have particularly strong seasonal river discharge variability, with long

Corresponding author: Ted Conroy, tconroy@uoregon.edu periods of low discharge during the dry season and event-driven periods (typically 1-5 days) of intense discharge during the wet season. These seasonal discharge variations result in large seasonal changes in the salinity distribution (Banas et al. 2004; Nidzieko and Monismith 2013; Sutherland and O'Neill 2016), and in extreme cases the salinity gradient can reverse in the dry season due to evaporation (Largier et al. 1997). The seasonal change in salinity distribution has been shown to alter the strength of gravitational circulation and subtidal currents (Nidzieko and Monismith 2013), however, the importance of the subtidal contribution to the exchange flow depends on the strength of tidal dispersive processes.

Many estuaries on the U.S. West Coast can be characterized as Mediterranean due to their small watersheds with minimal snowmelt. In summer, precipitation is rare and freshwater input decreases substantially, leading to large seasonal shifts in the salinity distribution in small to midsize estuaries (Banas et al. 2004; Sutherland and O'Neill 2016). Conditions in these estuaries can also be affected by shelf processes that modify coastal water 
properties and sea level (Hickey and Banas 2003; Giddings and MacCready 2017). For example, in Oregon, relatively fresh water can be advected along the shelf from the Columbia River (Hickey and Banas 2003) or from rivers in Southern Oregon and Northern California (Mazzini et al. 2014). During the dry season, upwelling can bring denser water with low dissolved oxygen and high nutrient levels into estuaries (Brown and Ozretich 2009; Roegner et al. 2011). However, it is not clear how the estuarine exchange flow, which facilitates the exchange between the coastal ocean and estuaries, varies seasonally in these small to midsize estuaries.

In estuaries that have strong tidal forcing and are relatively short (i.e., the length of salt intrusion is comparable to the tidal excursion), the landward salt flux due to correlations between the salinity and velocity at tidal time scales can be a substantial component of the salt balance (Hughes and Rattray 1980; Ralston et al. 2010; Chen et al. 2012). The tidal salt flux is typically characterized as a dispersive process acting on the subtidal along-channel salinity gradient (Fischer 1976). This dispersive transport is independent of the exchange flow due to gravitational circulation, and the relative contribution of the tidal and subtidal components of the salt flux varies across estuarine parameter space (Hansen and Rattray 1965) depending on the river discharge and tidal amplitude (Chen et al. 2012).

Here, we describe seasonal and tidal variations in hydrography, salt flux, and estuarine exchange flow in the Coos Estuary, Oregon, using observations and a numerical ocean model. The estuary has a seasonal salinity field, strong tidal forcing, is relatively short, and has multiple branching tributaries. The total exchange flow (TEF) method (MacCready 2011), as well as the Eulerian salt flux decomposition, is used to examine the influence of the seasonal changes in the river discharge and baroclinic pressure gradient on the estuarine exchange flow.

\section{The Coos Estuary}

The Coos Estuary (Fig. 1) is the second largest estuary in Oregon after the Columbia River Estuary in terms of surface area $\left(34 \mathrm{~km}^{2}\right)$ and volume $\left(0.14 \mathrm{~km}^{3}\right)$ (Hickey and Banas 2003). The Coos tidal prism is $\sim 30 \%$, which is less than in other small Oregon estuaries (typically $50 \%$ ) because of a deep, dredged navigational channel (Hickey and Banas 2003). Jetties flank the entrance (Fig. 1b), and in the estuary the dredged main channel connects to multiple shallower tributaries. The channel is $20 \mathrm{~m}$ deep at the mouth (Fig. 1c) and the narrow dredged channel (13-m depth, 91-m width) begins about $3 \mathrm{~km}$ into the estuary, adjacent to shoals and tidal flats. The dredged channel continues past the town of Coos Bay
$(23 \mathrm{~km})$ and terminates in Isthmus Slough $(25 \mathrm{~km})$, which is the deepest tributary in the estuary (7-m mean depth). Most tributaries are shallower and have sharp transitions with the dredged channel (Fig. 1c), including at South Slough (4-m mean channel depth) in the lower estuary and Marshfield Channel (4-m mean channel depth) where the Coos River enters the upper estuary (Fig. 1).

The Coos River inputs most of the freshwater into the estuary through Marshfield Channel and the East Bay tidal flats $(\sim 85 \%$ based on watershed area). River discharge $Q_{r}$ is highly seasonal and episodic (Fig. 2a), with typical discharge events of $50-500 \mathrm{~m}^{3} \mathrm{~s}^{-1}$ and background winter flows of $10-50 \mathrm{~m}^{3} \mathrm{~s}^{-1}$. During the summer, discharge from the Coos River falls to $1-2 \mathrm{~m}^{3} \mathrm{~s}^{-1}$. Several smaller creeks also enter the estuary, such as Winchester Creek (Fig. 1), where peak winter discharge events are $1-3 \mathrm{~m}^{3} \mathrm{~s}^{-1}$. The tides are mixed semidiurnal, having one strong ebb and flood each day (Fig. 3a). The mean tidal range is $1.7 \mathrm{~m}$, the mean diurnal range is $2.3 \mathrm{~m}$, and the difference in amplitude between spring and neap tides is typically $1.5 \mathrm{~m}$. Tidal currents are on the order of $1 \mathrm{~m} \mathrm{~s}^{-1}$, and tidal excursions are $8-15 \mathrm{~km}$ in the main channel.

The hydrography of the estuary varies with the seasonal forcing. Sutherland and O'Neill (2016) observed that the horizontal salinity gradient ranged from 0.12 to $1 \mathrm{psu} \mathrm{km}{ }^{-1}$ and the vertical salinity gradient ranged from 0.01 to $1.05 \mathrm{psu} \mathrm{m}^{-1}$. Due to the bathymetric and seasonal variability in discharge, different segments of the estuary fall into different parts of estuarine parameter space (Geyer and MacCready 2014). The main channel $(0-23 \mathrm{~km})$ encompasses a broad range of the parameter space, including the partially and well-mixed regimes [the mixing parameter $M$ ranges from 0.6 to 1.4 and the freshwater Froude number $\left(\mathrm{Fr}_{f}\right)$ ranges from $10^{-4}$ to $10^{-1}$, while the shallower regions and tributaries largely fall in the well-mixed and time-dependent salt wedge regimes $(M$ ranges from 1 to 1.8 and $\mathrm{Fr}_{f}$ ranges from $10^{-3}$ to 1 ). However, as will be shown, the exchange flow dynamics of the estuary as a whole are consistent with time-dependent tidal estuaries, due to its geometry, strong tidal forcing, and unsteadiness of the salinity distribution.

\section{Methods}

\section{a. Numerical ocean model}

We use the Finite Volume Coastal Ocean Model (FVCOM, v3.2.1) (Chen et al. 2003, 2013) to simulate flow and water properties in the Coos Estuary. FVCOM utilizes a finite volume discretization of the three-dimensional hydrostatic primitive equations that is well suited for simulating coastal and estuarine environments with complex geometries. The unstructured 

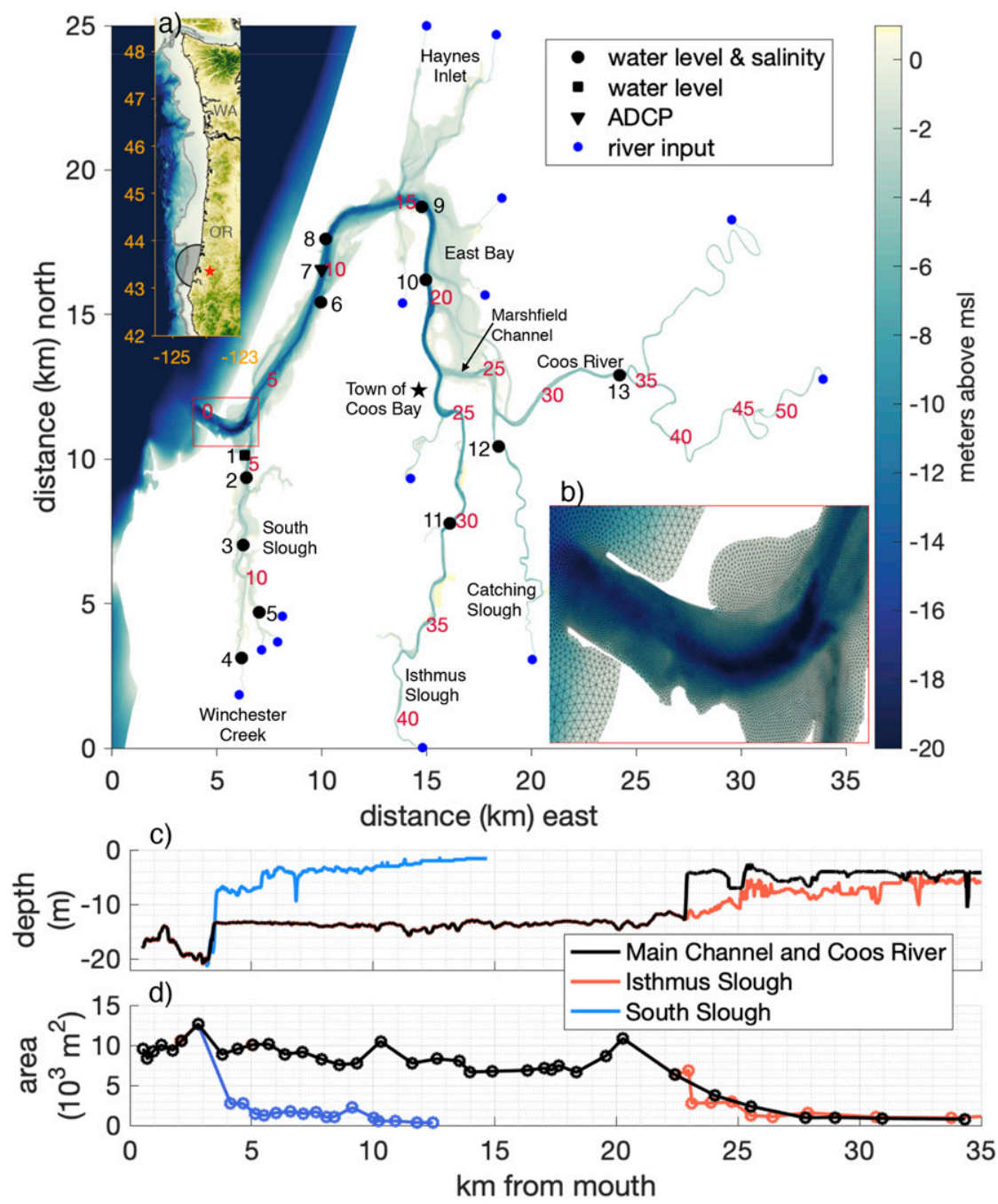

FIG. 1. (a) Elevation map of the U.S. Pacific Northwest coastline. The shelf break (200-m contour) is shaded in gray, and the numerical model domain is shown in the black outline. The red star shows the location of the Coos Estuary. The main figure shows the bathymetry of the estuary ( $\mathrm{m}$ referenced to mean sea level) and numerical model domain of the Coos Estuary. The red labels correspond to distance $(\mathrm{km})$ from the mouth of the estuary along the thalweg. The observational stations are labeled numerically on the map, and the corresponding names of the stations are listed in Table 1. (b) The unstructured numerical model grid at the mouth of the estuary, which is outlined in red in the main figure. (c) Depth of the thalweg (m) up the Coos River, Isthmus Slough, and South Slough. (d) Mean cross-sectional area $\left(\mathrm{m}^{2}\right)$ of channels in (c). The points represent cross sections where flux calculations are performed.

grid allows variable horizontal resolution, here typically $15 \mathrm{~m}$ within the estuary (Fig. 1b), with resolution concentrated along the thalweg and adjacent shoals, and telescoping to $3 \mathrm{~km}$ at open boundaries. High spatial resolution (as in the grid used here) in regions of strong velocity and salinity gradients was found to reduce numerical diffusion of salinity in the Connecticut River Estuary, a time-dependent salt wedge estuary (Ralston et al. 2017). FVCOM employs the $k-\varepsilon$ turbulence closure scheme from the General Ocean Turbulence Model
(Umlauf and Burchard 2003). We set the horizontal diffusion coefficient to zero. FVCOM allows wetting and drying in intertidal areas, which compose roughly half of the estuary area. We use 20 sigma layers in the vertical, and the grid has 195000 triangular elements and 103000 nodes.

\section{1) BATHYMETRY}

Bathymetry in the model is from a water-penetrating airborne lidar survey gridded at 1-m spacing (https:// coast.noaa.gov/htdata/lidar1_z/geoid12b/data/4905/), 


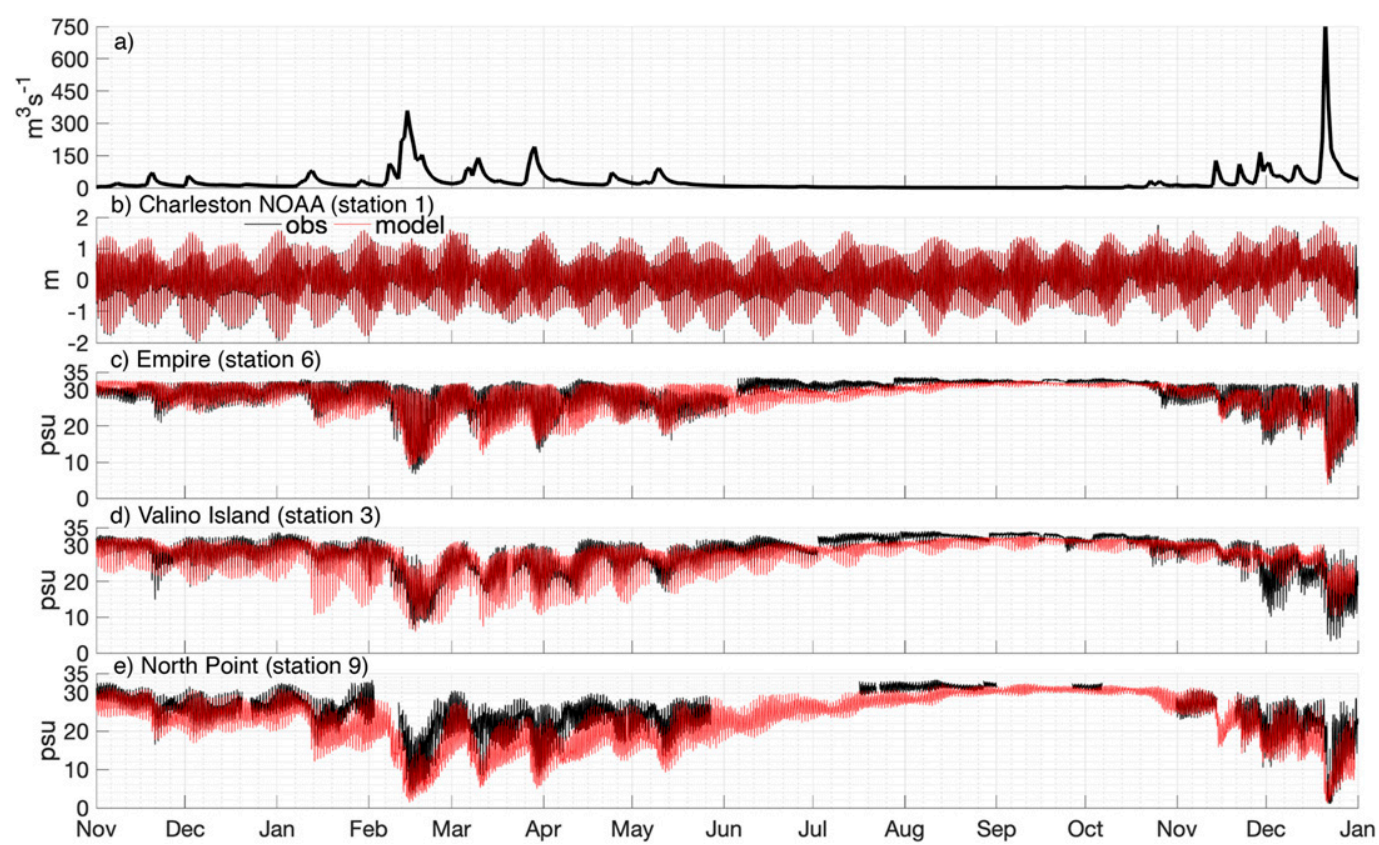

FIG. 2. (a) Coos River freshwater discharge $\left(\mathrm{m}^{3} \mathrm{~s}^{-1}\right)$ from November 2013 to January 2015. (b)-(e) Model-data time series comparisons with observations colored black and modeled values red. The station numbers correspond to Fig. 1 and Table 1. Shown in (b) is the tidal amplitude (m) at Charleston. Also shown are salinity (psu) at the Empire, Valino Island, and North Point stations in (c)-(e), respectively.

complemented by single-beam sonar collected from a Coastal Profiling System (Ruggiero et al. 2007) and channel surveys from the U.S. Army Corps of Engineers. Bathymetry data were weight interpolated using
MB-system (https://www.mbari.org/products/researchsoftware/mb-system/) onto the model grid. For areas where limited bathymetry data exist, such as in the upper reaches of smaller channels, a linear along-channel slope

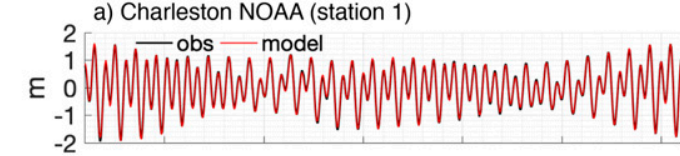

b) ADCP location (station 7)

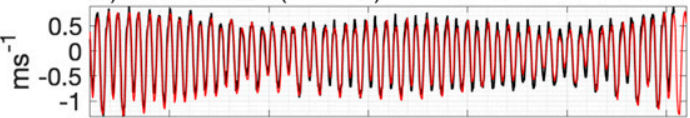

35 c) Empire (station 6)
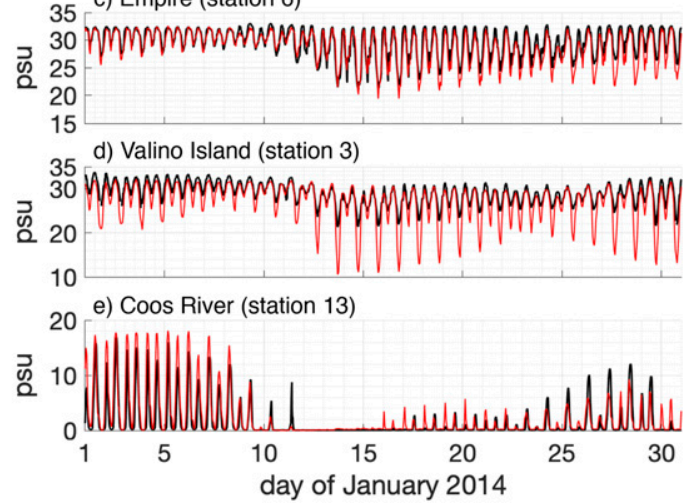
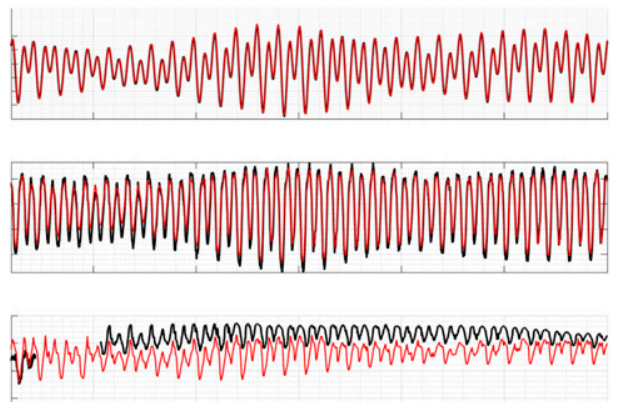

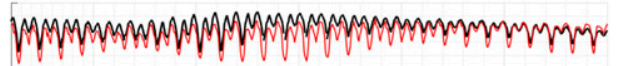

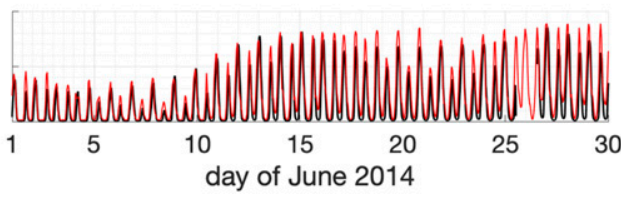

FIG. 3. Model-data comparisons for the months of (left) January 2014 and (right) June 2014. Observations are black and modeled values are red. (a) Tidal amplitude (m) at Charleston. (b) Depth-averaged along-channel velocity $\left(\mathrm{m} \mathrm{s}^{-1}\right)$ at station 7. (c)-(e) Salinity (psu) at the Empire, Valino Island, and Coos River stations, respectively. 
TABLE 1. Model skill metrics for each station in the estuary (Fig. 1). The sensor and water column depth (m below mean sea level), correlation coefficient $\left(r^{2}\right)$, model skill score [SS, Eq. (9)], and the mean bias (MB) are shown for water level, salinity, and depth-averaged velocity time series.

\begin{tabular}{lcccc}
\hline \hline \multicolumn{1}{c}{ Station } & $\begin{array}{c}\text { Sensor/water column depth } \\
(\mathrm{m} \text { below MSL) }\end{array}$ & $\begin{array}{c}\text { Water level: } \\
r^{2}(\mathrm{SS})\end{array}$ & $\begin{array}{c}\text { Salinity: } \\
r^{2}(\mathrm{SS})(\mathrm{MB})\end{array}$ & $\begin{array}{c}\text { Velocity: } \\
r^{2}(\mathrm{SS})\end{array}$ \\
\hline 1) Charleston (NOAA) & -15.3 & $0.996(0.997)$ & - & - \\
2) Charleston (SSNERR) & $2.3 / 3.7$ & $0.996(0.995)$ & $0.810(0.773)(0.027)$ & - \\
3) Valino Island & $1.8 / 2.2$ & $0.990(0.989)$ & $0.780(0.751)(0.017)$ & - \\
4) Winchester Creek & $1.0 / 1.8$ & $0.947(0.902)$ & $0.305(0.098)(0.334)$ & - \\
5) Elliot Creek & $1.5 / 2.0$ & $0.970(0.970)$ & $0.629(0.342)(0.312)$ & - \\
6) Empire & $5.4 / 5.9$ & - & $0.731(0.723)(0.030)$ & - \\
7) ADCP location & $9.8 / 10.6$ & - & - & - \\
8) BLM & $4.7 / 6.7$ & $0.986(0.983)$ & $0.846(0.589)(0.030)$ & - \\
9) North Point & $6.0 / 7.9$ & $0.986(0.986)$ & $0.720(0.110)(0.220)$ & - \\
10) Coquille & $9.0 / 12.4$ & - & $0.531(-0.776)(1.150)$ & - \\
11) Isthmus Slough & $2.2 / 7.0$ & $0.974(0.973)$ & $0.615(0.204)(0.012)$ & - \\
12) Catching Slough & $2.9 / 5.3$ & $0.976(0.970)$ & $0.748(0.608)(0.183)$ & - \\
13) Coos River & $1.9 / 4.0$ & $0.974(0.968)$ & $0.748(0.612)(0.138)$ & - \\
\hline
\end{tabular}

with uniform across-channel depth was prescribed. The bottom roughness length scale $z_{0}$ was calibrated based on comparison to water level observations to a spatially uniform value of $0.002 \mathrm{~m}$.

\section{2) BOUNDARY CONDITIONS}

Boundary conditions include river discharge at fourteen locations (Fig. 1) and tidal forcing at the open boundary. Freshwater discharge data from the Coos Watershed Association (http://www.cooswatershed.org/) is used for the Coos River, while the remaining smaller, ungauged freshwater inputs are estimated by scaling the relative watershed areas with discharge data from Marlow Creek, the smallest tributary that was gauged during the study period. The scaling reproduces the discharge variability and magnitude at Winchester Creek, which was gauged prior to the study period. The model is forced at the open boundary with elevations from the TXPO Tidal Model Driver (Egbert and Erofeeva 2002), using 13 tidal constituents. Subtidal water levels from the Charleston tide gauge (NOAA station 9432780) are added to the TXPO water elevations to incorporate subtidal variability. Salinity boundary conditions stem from a regional ocean model of the U.S. Pacific Northwest (Giddings et al. 2014). Temperature is not included in the equation of state, as salinity dominates the density structure in the estuary. We spin the model up for one month prior to the first discharge event of water year 2014 to obtain a representative initial salinity structure.

\section{b. Observational data}

We utilize observations from 2014 to describe the hydrography and validate the model. The Charleston tide gauge (NOAA station 9432780) and water quality sensors
(YSI model 6600) maintained by the South Slough National Estuarine Research Reserve (SSNERR) provide water elevations and salinity time series. SSNERR maintains sensors in Charleston (station 2, Fig. 1), Valino Island (station 3), Winchester Creek (station 4), Elliot Creek (station 5), as well as stations periodically maintained in the upper estuary: North Point (station 9), Isthmus Slough (station 11), Catching Slough (station 12), and in the Coos River (station 13). Two additional water quality sensors are maintained by the Confederated Tribes of the Coos, Lower Umpqua, and Siuslaw water quality monitoring program, at the Empire Docks (station 6) and Bureau of Land Management boat ramp (station 8). For each location, the water column depth and depth of the water quality sensor are given in Table 1 . Monthly along-channel conductivity-temperature-depth (CTD) profiles were collected from 2012 to 2014 (Sutherland and O'Neill 2016). An upward looking Sontek 150$\mathrm{kHz}$ acoustic Doppler current profiler (ADCP) was deployed from fall 2013 to summer 2014, located on the channel flank (10-m depth) near the Empire Docks (station 7).

\section{c. Total exchange flow and salt balance}

We use the isohaline total exchange flow (MacCready 2011) method to quantify the exchange flow in the estuary. TEF has the advantage of incorporating subtidal and tidal fluxes of volume and salt, and exactly satisfying the time-dependent Knudsen relations (Burchard et al. 2018). Volume transport through a cross section is classified as a function of salinity class, and it includes transport due to both tidal and subtidal (e.g., river discharge, Stokes drift, gravitational circulation, sea level setup/down) processes. 
Following MacCready (2011), we define the isohaline transport function as

$$
Q(s)=\left\langle\int_{A_{s}} u d A\right\rangle,
$$

where $A_{s}$ is the area of a cross-sectional element that has salinity greater than $s, u$ is the velocity normal to the cross section, $d A$ is the area of the cross-sectional element, and the angle brackets indicate an average over the tidal cycle. In this study, all tidal averaging is done with a successive 24-24-25-h Godin filter. For the TEF method, we found that an output interval of $15 \mathrm{~min}$ or less is required to not alias volume transports in salinity classes, as hourly output created a noisy $Q(s)$ function. Due to computational constraints, we use hourly output for flux calculations for the full study period, and 15-min output when investigating the structure of $Q(s)$ (e.g., Fig. 10). The use of hourly output slightly decreased the magnitude of the calculated exchange flow but showed similar spatial and temporal patterns.

Formally, to find the transport in a specific salinity class $\delta s, Q(s)$ is differentiated as

$$
\frac{-\partial Q}{\partial s}=\lim _{\delta s \rightarrow 0} \frac{Q(s+0.5 \delta s)-Q(s-0.5 \delta s)}{\delta s} .
$$

In practice, we bin salinity and volume fluxes using 1000 salinity bins. The global maximum of $Q(s)$ is used to define the inflowing and outflowing components, as discussed in MacCready et al. (2018),

$$
Q_{\text {in }}=\int \frac{-\partial Q(\text { in })}{\partial s} d s, \quad Q_{\text {out }}=\int \frac{-\partial Q(\text { out })}{\partial s} d s,
$$

where in denotes salinity bins from the maximum of $Q(s)$ to the maximum salinity and out denotes salinity bins from $0 \mathrm{psu}$ to the maximum of $Q(s)$. This binning method, compared to binning based on the sign of volume transport (e.g., MacCready 2011), is more robust as it is less sensitive to the number of salinity bins used (MacCready et al. 2018; Lorenz et al. 2019). The inward and outward fluxes of salt through a cross section are defined as

$$
F_{\text {in }}=\int s \frac{-\partial Q(\text { in })}{\partial s} d s, \quad F_{\text {out }}=\int s \frac{-\partial Q(\text { out })}{\partial s} d s,
$$

and the normalized salinities of the inflow and outflow are

$$
s_{\text {in }}=\frac{F_{\text {in }}}{Q_{\text {in }}}, \quad s_{\text {out }}=\frac{F_{\text {out }}}{Q_{\text {out }}} .
$$

The TEF terms exactly satisfy the time-dependent conservation of volume $\left(Q_{\text {in }}+Q_{r}+d V / d t=Q_{\text {out }}\right)$ and conservation of salt $\left(d S / d t=F_{\text {in }}+F_{\text {out }}\right)$, where $V$ is the subtidal integrated volume of the estuary (defined as the model domain landward of the mouth of the estuary), and $S$ is the subtidal salt content landward of the mouth of the estuary. The tidal volume flux magnitude $Q_{\text {tide }}$ is defined as

$$
Q_{\text {tide }}=\left\langle\int u d A\right\rangle .
$$

The TEF salt fluxes through a cross section can also be decomposed into a subtidal, spatially varying component, and a remainder that is due to tidal time-scale correlations, much like the classical salt flux decomposition method (e.g., Lerczak et al. 2006). Following several authors (MacCready 2011; Chen et al. 2012; Rayson et al. 2017), the TEF equivalent of the subtidal contribution, the Eulerian component, is defined as

$$
Q^{\mathrm{Eul}}(s)=\int_{\left\langle A_{s}\right\rangle}\langle u\rangle\langle d A\rangle,
$$

where the subtidal velocity through a cross section is binned by the subtidal salinity, then multiplied by the subtidal area $\left\langle A_{s}\right\rangle$. This formulation is different than summing subtidal volume fluxes in and out of the cross section, as $Q^{\mathrm{Eul}}$ is dependent on salinity class; the two quantities would be equal if the subtidal volume fluxes going in or out have nonoverlapping salinities. The subtidal component represents the magnitude of the TEF that is due to the subtidal salinity and velocity alone, and the tidal component of the TEF is defined as the remainder from the total $Q_{\mathrm{in}}^{T}=Q_{\mathrm{in}}-Q_{\mathrm{in}}^{\mathrm{Eul}}$.

In the classical flux decomposition method (Fischer 1976; Lerczak et al. 2006; Ralston et al. 2010), volume and salt fluxes are calculated spatially in a cross section rather than as a function of salinity class, and the subtidal and tidal contributions are separated by temporal averaging. The advective barotropic river flux $F_{R}$ pushes salt out of the estuary, and the spatial correlations at subtidal time scales due to processes such as gravitational circulation $F_{\text {Eul }}$ or the spatial and temporal correlations in the tidal oscillatory salt flux $F_{T}$ generally transport salt landward. The unsteady salt balance can be expressed in terms of both the TEF and Eulerian approaches,

$$
\frac{d S}{d t}=F_{\text {in }}+F_{\text {out }}=F_{R}+F_{\text {Eul }}+F_{T},
$$

where the three terms on the right-hand side of the equation are calculated as in Lerczak et al. (2006) and 
MacCready and Banas (2011). The tidal salt flux can also be represented as a dispersive process acting on the mean salinity gradient, $F_{T}=a_{0} K \partial s_{0} / \partial x$, where $a_{0}$ is the tidally filtered cross-sectional area, $s_{0}$ is the tidally filtered, cross-sectionally averaged salinity, and $K$ is the along-channel tidal dispersion coefficient.

Calculated volume and salt fluxes do not exactly balance the time-dependent volume or salt in the estuary due to errors associated with the mode-split (barotropic/baroclinic) time stepping combined with wetting and drying (Chen et al. 2013). This discrepancy in the calculated flux is due to the wet-dry interface moving across grid cells during a baroclinic time step. Based on idealized model studies the error increases with the mode-split factor, with tidal amplitude, and for milder intertidal slopes. Using a mode-split factor of 1 eliminates the discrepancy but is extremely computationally expensive and not practical for a high-resolution model domain.

We use a mode-split ratio of 10 and estimate the magnitude of the associated error in the calculated flux by running the model with simplified forcing (no river input or subtidal water level forcing), and calculating the subtidal volume transport through cross sections along the estuary. The volume flux error was found to be a function of tidal amplitude and varied from 3 to $30 \mathrm{~m}^{3} \mathrm{~s}^{-1}$ (out of the estuary) for neap and spring tides. The error is only associated with fluxes calculated from model output, and volume and salt are conserved in the model simulations because they are calculated at the barotropic time step. The salt flux error at the mouth was found to vary between 100 and $500 \mathrm{psu} \mathrm{m}^{3} \mathrm{~s}^{-1}$ out of the estuary, estimated by comparing the calculated fluxes $\left(F_{\text {in }}+F_{\text {out }}\right)$ with the change in estuarine salt content $d S / d t$. The error in salt flux calculation is small compared with the TEF salt fluxes $(1 \%-5 \%)$. In the Eulerian decomposition, the calculated error was added to $F_{R}$ so that Eq. (8) balances.

\section{Model evaluation}

Model performance was assessed with the correlation coefficient $\left(r^{2}\right)$ and skill score (SS) (Table 1). Following Murphy (1988), the skill score is defined as

$$
\mathrm{SS}=1-\frac{1}{\sigma_{o}^{2} N} \sum_{i=1}^{N}\left(x_{o}-x_{m}\right)^{2},
$$

where $\sigma$ is the standard deviation, $o$ is the observed and $m$ is the modeled value of a variable $x$. The skill score can also be written as

$$
\mathrm{SS}=r^{2}-\left(r-\frac{\sigma_{m}}{\sigma_{o}}\right)^{2}-\left(\overline{\frac{x_{m}-\overline{x_{o}}}{\sigma_{o}}}\right)^{2},
$$

where an overbar represents the mean, the middle term on the right side of the equation represents the normalized variance bias between the model and observations, and the last term represents the normalized mean bias (MB) between the model and observations. $\mathrm{MB}$ is calculated for salinity time series comparisons (Table 1), because for multiple stations MB causes a larger reduction in SS than the variance bias (e.g., the model is too fresh, but is simulating the variance properly).

At seasonal to annual time scales, the model simulates well the variation in salinity with river discharge and water level (Fig. 2). The model closely corresponds with observations near the mouth (Fig. 2c) with $r^{2}=0.731$ and SS $=0.723$ at Empire (Table 1), and matches the temporal variability correctly in stations up estuary but is generally too fresh (e.g., North Point; Fig. 2e). At North Point the skill score is relatively low $(\mathrm{SS}=0.110$; Table 1) due to the mean fresh bias $(\mathrm{MB}=0.220)$.

The model has high $r^{2}$ and SS for tidal elevation throughout the estuary (Table 1), with maximum skill nearest the mouth and lower skill in the shallower tributaries. Conroy (2019) computed the amplitudes and phases of major tidal constituents with T-TIDE (Pawlowicz et al. 2002) and found water levels roughly $90^{\circ}$ out of phase with velocity in both observations and model. Along the main channel the tidal amplitude increases from the mouth and reaches its maximum in Isthmus Slough in both observations and the model, and then generally decreases in the shallower tributaries (Table 1; Conroy 2019).

Model comparisons are shown with observations for a month in the wet and dry seasons (Fig. 3). The model captures the spring-neap variation in tidal amplitude and depth averaged velocity (Fig. 3). The model reproduces the tidal asymmetry in current strength (Fig. 3b) as well as the fortnightly modulation. The velocity is strongest during ebb tides, where surface currents range from greater than $1.5 \mathrm{~m} \mathrm{~s}^{-1}$ during spring tides to $0.8 \mathrm{~m} \mathrm{~s}^{-1}$ during neap tides, and the flood tides do not exceed $1 \mathrm{~m} \mathrm{~s}^{-1}$. The subtidal along-channel velocity from the model shows a two-layer structure that is consistent with observations (not shown), and is stronger during neap tides and the wet season. Tidal variability in salinity is greatest during spring tides when velocities are maximum (Figs. 3c-e). While the model has a mean fresh bias of roughly 3 psu in the main channel in the dry season (Figs. 3c,d), it simulates well the salinity variability at the Coos River sensor located $33 \mathrm{~km}$ from the mouth (station 13; Fig. 3e). This correspondence near the landward limit of the estuary make the model useful for assessing the salinity intrusion throughout the year. 
a) February 222014

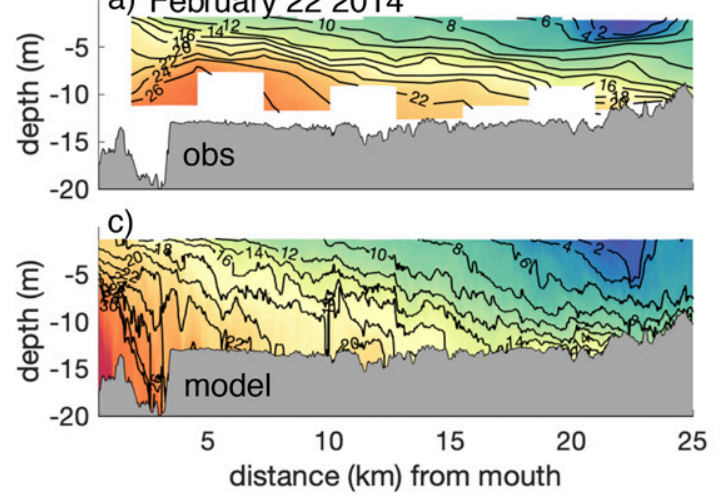

e)

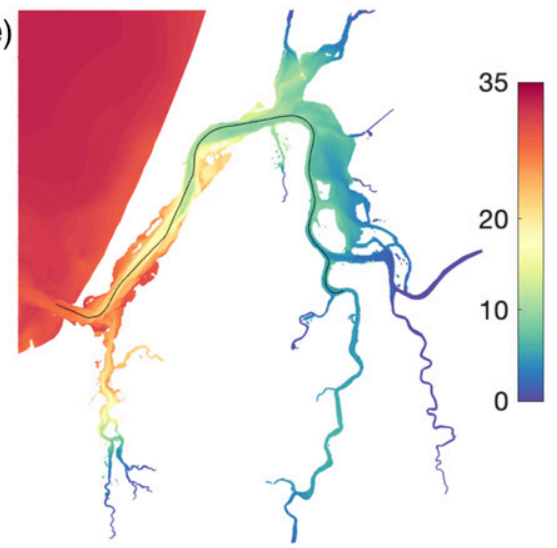

b)
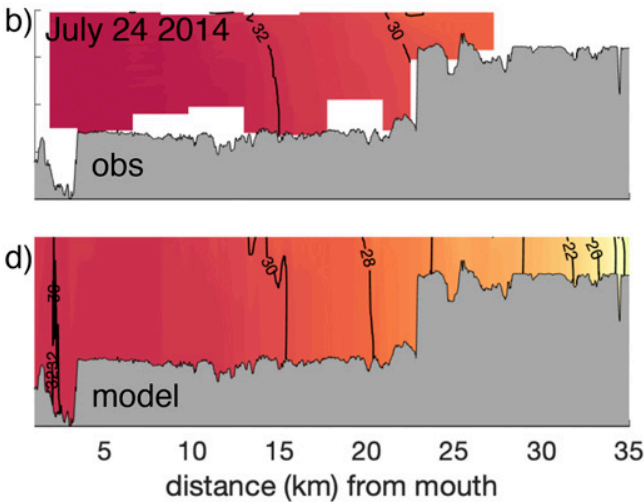

f)

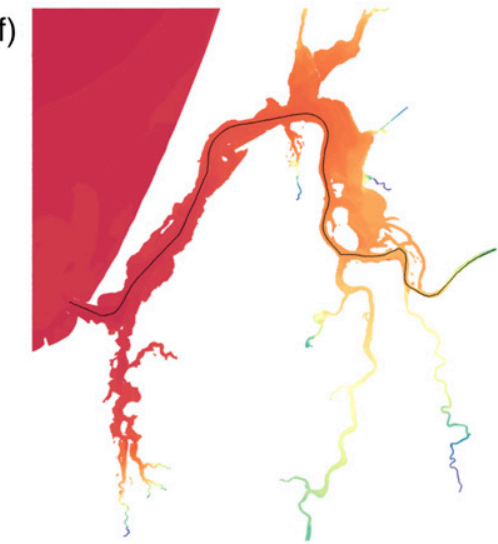

FIG. 4. Along-estuary salinity (psu) comparisons between (a),(b) observed and (c),(d) modeled fields for (left) $22 \mathrm{Feb} 2014$ and (right) $24 \mathrm{Jul} 2014$. (e),(f) Surface salinity from the model at the same time as the CTD profiles above. The location of each transect is shown by the black line for each day. The color bar for all plots is shown in (e).

We compare along-estuary CTD profiles collected at monthly intervals from October 2013 to July 2014 (136 profiles total; Sutherland and O'Neill 2016) to the simulated salinity fields. The model captures the seasonal variability in the along-channel salinity distribution, including the depth averaged salinity $\left(r^{2}=0.84\right.$, $\mathrm{SS}=0.68)$, top to bottom salinity difference $\Delta s\left(r^{2}=\right.$ $0.60, \mathrm{SS}=0.43)$ and the horizontal salinity gradient $\left(r^{2}=\right.$ $0.88, \mathrm{SS}=0.68)$. Similar to the time series data, the CTD profiles indicate a fresh bias, with the model on average 0.70 psu fresher and $\Delta s 2.1$ psu less stratified. The model represents well the spatial structure, including the fresher water entering the main channel from Marshfield Channel (2-psu isohaline Figs. 4a,c). However, the model does not fully reproduce the wintertime stratification (Fig. 4a) and is slightly fresh overall in summer (Fig. 4d).

In summary, the model has high skill for tidal propagation (Table 1), moderately good skill for salinity, and good skill for depth-averaged velocity. The model has a mean fresh bias that may be due to multiple factors, such as overestimated freshwater fluxes, unknown bathymetry in the upper reaches of channels, poorly constrained salinity boundary conditions, or numerical diffusion reducing the landward salt transport. At shallow locations, small changes in freshwater flux can change the location of salinity fronts, such as in Winchester Creek, where the model does not capture the extreme tidal variability associated with tidal advection of a salinity front. Improving model performance would likely entail collecting more accurate bathymetry for the upper reaches and empirically obtaining better estimates for freshwater discharge from the smaller creeks.

\section{Results}

\section{a. Tidal variability}

To illustrate the tidal variability, we show time series of velocity and salinity (Fig. 5) during a discharge event on 13 January $2014\left(Q_{r} \approx 85 \mathrm{~m}^{3} \mathrm{~s}^{-1}\right)$. At the end of flood (Fig. 5a, time 1), currents in the main channel are still flowing landward with nearly vertical isohalines throughout the estuary. The tide is close to a standing wave in the main channel, such that slack currents occur shortly after high water. Velocity is greatest in the thalweg, and differential advection creates lateral salinity gradients that 

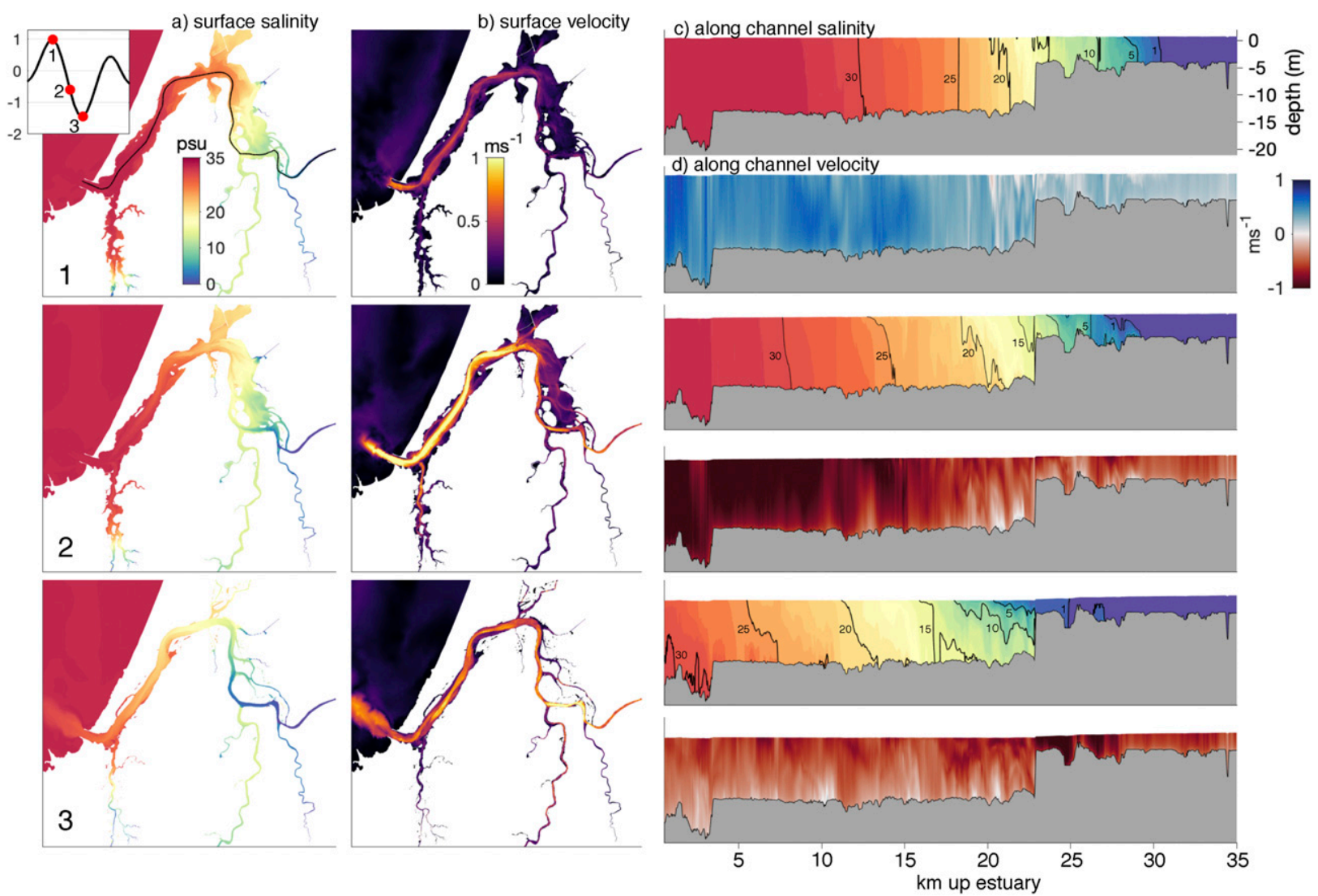

FIG. 5. Salinity and velocity structure on 13 Jan 2014 at three times during the tidal cycle, shown by the inset in the upper-left corner (water level at station $1 ; \mathrm{m}$ ). For each time shown are the (a) surface salinity (psu), (b) magnitude of surface velocity (m s ${ }^{-1}$ ), (c) alongchannel salinity (psu), and (d) along-channel velocity $\left(\mathrm{m} \mathrm{s}^{-1}\right)$. The along-estuary transect used in (c) and (d) is colored in black on the surface salinity plot at time 1 .

induce a two-celled lateral circulation with midchannel convergence (Nunes and Simpson 1985) from 2 to $16 \mathrm{~km}$ from the mouth (not shown). The shallower regions of the estuary begin to ebb while the main channel is still flooding. This creates frontal convergence zones in multiple locations, particularly in the East Bay (Fig. 5; $15-20 \mathrm{~km})$.

During ebb the stratification increases (Fig. 5, time 2-3) due to the vertical shear in velocity and advection of the horizontal salinity gradient. Freshwater is advected out of Marshfield Channel into the upper water column of the main channel (Fig. 5, time 2-3). A large portion of the estuary goes dry during ebb, particularly in the East Bay (Fig. 5, time 3).

The salinity variability of South Slough and Isthmus Slough during a tidal cycle are shown in Fig. 6. At the junction of the Marshfield Channel with Isthmus Slough ( $23 \mathrm{~km}$ from mouth), freshwater input from the Coos River creates a sharp horizontal salinity gradient that is maintained for the duration of ebb, creating a reversal in the along-channel salinity gradient. Freshwater from
Marshfield Channel can be seen in the along-channel transect up Isthmus Slough (Fig. 6). During the following flood, the pulse of fresher water is advected up Isthmus Slough. A reversal in the along-channel salinity gradient that is maximum during ebb is also found at the mouth of South Slough near the mouth of the main estuary (Fig. 6). Similar features were documented at tidal channel junctions in San Francisco Bay (Warner et al. 2002; MacVean and Stacey 2011), where reversals in the along-channel salinity gradient at channel junctions created convergences in the along-channel subtidal velocity.

\section{b. Seasonal variability}

Seasonally, the total salt content and hydrography of the estuary change dramatically with river discharge (Figs. 7a-d). The subtidal total salt content $S$ changes by a factor of 2 over the year (Fig. 7b), rapidly decreasing in the fall due to discharge events and slowly increasing during the dry season beginning in June. Similar to the salt content, $\partial s / \partial x$ varies with river discharge 


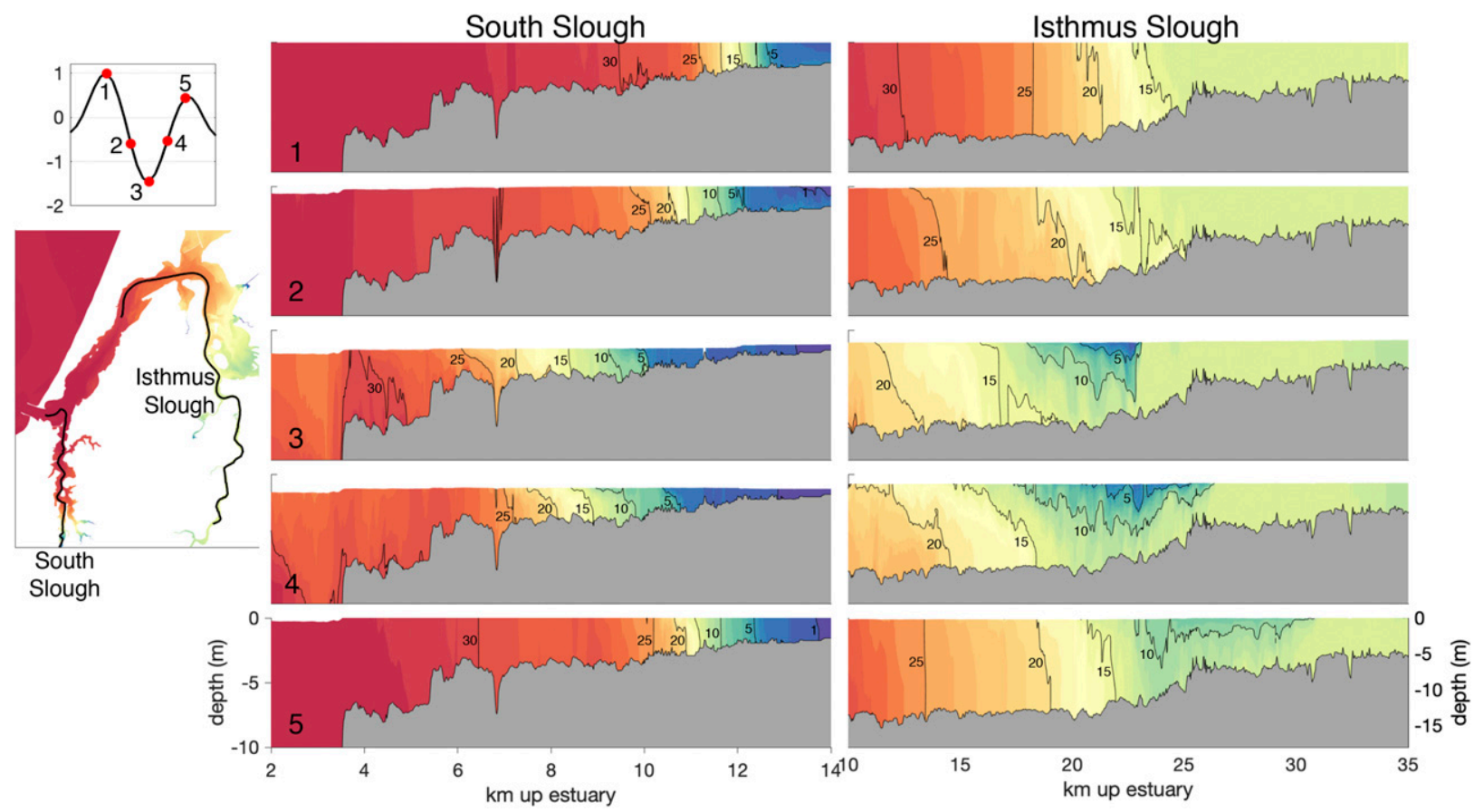

FIG. 6. Along-estuary salinity (psu) in (left) South Slough and (right) Isthmus Slough at times corresponding with the inset in the upper left (water level at station 1; m) on 13 Jan 2014. The transect locations are shown in the lower-left inset.

(Fig. 7c) and annually ranges from 0.5 to $1.5 \mathrm{psu} \mathrm{km}^{-1}$. Here $\partial s / \partial x$ is calculated as the gradient from the mouth to the landward extent of the depth averaged 2-psu isohaline in Marshfield Channel. During the study period, the 2-psu isohaline only moved seaward of Marshfield (Fig. 1c) during the largest discharge event in December $2014\left(Q_{r} \approx 800 \mathrm{~m}^{3} \mathrm{~s}^{-1}\right)$. The sharp increase in depth at this junction (Fig. 1c) decreases the mean river velocity and associated seaward salt flux, effectively setting a minimum length of the salinity intrusion or alternatively an upper limit on $\partial s / \partial x$ around 1.4 psu km$^{-1}$ (Fig. 7c).

Vertical stratification $\Delta s$ at the mouth is maximum during the wet season and also varies with $Q_{R}$ (Fig. 7d), ranging from 5 to $15 \mathrm{psu}$. The subtidal $\Delta s$ is much smaller than the tidal maximum stratification, and the TEF $\Delta s$ is between the two (2-9 psu). During the dry season, $\Delta s$ drops to values between 0 and 2 psu.

The subtidal along-channel salt balance at the mouth is dominated by three terms throughout the year: the river flux $F_{R}$, tidal flux $F_{T}$, and unsteadiness $d S / d t$ (Fig. 7e), with the steady flux $F_{\text {Eul }}$ generally small. All terms are greatest during the wet season, corresponding with the greatest along-channel salinity gradient. Tidal flux $F_{T}$ is the largest positive salt flux contribution, ranging from approximately 100 to $12000 \mathrm{psu} \mathrm{m}^{3} \mathrm{~s}^{-1}$ and is generally around $1000 \mathrm{psu} \mathrm{m}^{3} \mathrm{~s}^{-1}$. River flux $F_{R}$ varies with $Q_{r}$, but $F_{R}$ and $F_{T}$ are out of phase, maintaining $d S / d t$ as a significant component of the salt balance.

During the dry season, the salt balance is maintained by $F_{R}, F_{T}$, and $d S / d t$. Although $Q_{r}$ drops substantially, $F_{R}$ is the main contributor to variation in $d S / d t$, caused by sea level setup and setdown $(d V / d t)$ associated with along-coast winds that cause a barotropic salt flux that is incorporated into $F_{R}$ (Chen and Sanford 2009).

Scaling of the salt balance [Eq. (8)] can be used to relate the steady-state salinity distribution to the river discharge, resulting in power law relationships between $Q_{r}$ and the length of the salinity intrusion (i.e., $\partial s / \partial x$ ) (MacCready and Geyer 2010). In estuaries where gravitational circulation dominates the salt flux, $\partial s / \partial x$ varies weakly with discharge, as $Q_{r}^{1 / 3}$. In estuaries where tidal dispersion dominates the salt flux, the expected scaling for $\partial s / \partial x$ is stronger, as $Q_{r}^{1}$ (Hansen and Rattray 1965; Monismith et al. 2002). In the Coos Estuary model, $\partial s / \partial x$ varies as $Q_{r}^{0.10}\left(r^{2}=0.87\right.$; Fig. 8a) compared with $Q_{r}^{0.19}$ based on monthly along-estuary CTD surveys in the main channel (Sutherland and O'Neill 2016).

The total salt content $S$ also varies seasonally with $Q_{r}$, changing by a factor of 2 over the study period (Fig. 8b). $S$ displays seasonal hysteresis, having a different salt content for a given discharge in the wet and dry seasons. For example at $Q_{r} \approx 10 \mathrm{~m}^{3} \mathrm{~s}^{-1}$, the salt content ranges from 0.42 to $0.5610^{10} \mathrm{psu} \mathrm{m}^{3}$ at the 


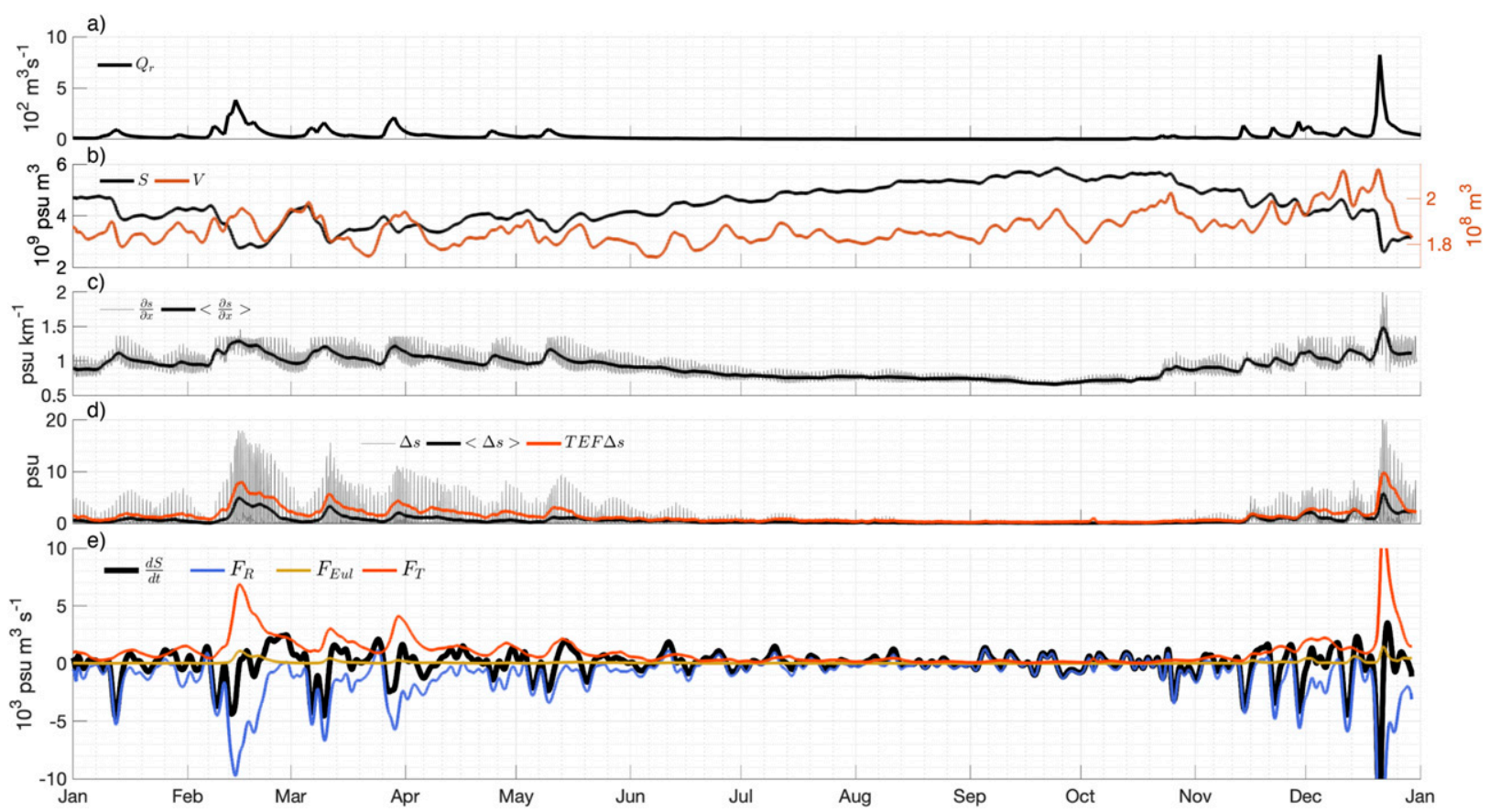

FIG. 7. (a) Coos River discharge $\left(\mathrm{m}^{3} \mathrm{~s}^{-1}\right)$ over 2014. (b) Tidally filtered total salt content $\left(10^{10} \mathrm{psu} \mathrm{m}^{3}\right)$ in the estuary throughout 2014 (black line) and the tidally filtered estuarine water volume $\left(10^{8} \mathrm{~m}^{3}\right)$ in orange. (c) The horizontal salinity gradient $\left(\mathrm{psu} \mathrm{km}^{-1}\right)$, calculated from the mouth of the estuary up Marshfield Channel and the Coos River, terminating at the depth-averaged 2-psu isohaline. The gray line shows tidal variability while the black line is tidally filtered. (d) Vertical stratification $(\Delta s)$ at the mouth of the estuary. The gray line is the top to bottom salinity difference (psu) located at a point in the center of the channel, and the black line is tidally filtered. The TEF stratification at the mouth is shown in orange. Note that the Eulerian TEF stratification closely resembles the black line. (e) Eulerian salt flux decomposition evaluated at the mouth of the estuary, including unsteadiness $d S / d t$, the barotropic river flux $F_{R}$, the Eulerian flux $F_{\text {Eul }}$, and the tidal flux $F_{T}$.

beginning of the dry season and beginning of the wet season, respectively.

\section{c. Exchange flow variability}

We apply the TEF method to quantify the seasonal variation in the estuarine exchange flow. The inflowing component of the exchange $Q_{\text {in }}$ at the mouth varies between 200 and $1200 \mathrm{~m}^{3} \mathrm{~s}^{-1}$, in phase with the springneap cycle $\left(Q_{\text {tide }}\right)$ (Fig. 9). Exchange flow is greater during spring tides and reduced during neap tides. The tidal component of exchange flow $Q_{\text {in }}^{T}$ accounts for most of the variability in $Q_{\text {in }}(80 \%-95 \%$ at the mouth), and $Q_{\mathrm{in}}^{\mathrm{Eul}}$ is small in most of the estuary. While the total $Q_{r}$ into the estuary varied from 0.8 to $820 \mathrm{~m}^{3} \mathrm{~s}^{-1}$, there is little seasonal change in $Q_{\text {in }}$, in contrast with the outflowing component $Q_{\text {out }}$ that varies seasonally with $Q_{r}$.

We compare snapshots of the along-estuary variability in the exchange flow (Fig. 9c-f) to the annual mean (Fig. 9g). Through most of the estuary, the tidal flux is the largest component of $Q_{\text {in }}$. While $Q_{\text {in }}$ is largely a function of tidal amplitude, the river discharge influences the partitioning between $Q_{\mathrm{in}}^{\mathrm{Eul}}$ and $Q_{\mathrm{in}}^{T}$ as well as the magnitude of $Q_{\text {out }}$ (Figs. 9c,d). During discharge events $Q_{\mathrm{in}}^{\text {Eul }}$ generally increases from 3 to $14 \mathrm{~km}$, and $Q_{\mathrm{in}}^{T}$ is large near the mouth but decreases up estuary, going negative in some regions. The total exchange flow is weaker during neap tides (Fig. 9e), and during the dry season $Q_{\mathrm{in}}^{T}$ accounts for most of the variability in $Q_{\text {in }}$ (Figs. 9b,f).

\section{d. Tributary exchange}

The shallower tributaries of the estuary exhibit similar temporal patterns in exchange flow as the main channel. However, examination of the exchange flow in salinity classes $(\partial Q / \partial s)$ at channel junctions reveals a division into three, rather than two, main salinity classes (e.g., Fig. 10b). Two familiar salinity classes represent 1) fresher water sourced from the Coos River, and 2) saltier ocean water, both of which are transported into the tributary (Fig. 6). The third class is an intermediate salinity water that is exported from the tributary, as observed previously at the entrance of South Slough (Roegner and Shanks 2001).

Separation of the exchange into three salinity classes persists for the duration of the study period for South Slough (Fig. 10b), but is not unique to that junction. At the entrance to Isthmus Slough, there is greater complexity in $\partial Q / \partial s$ (Fig. 10d) due to the proximity to the Coos River freshwater source. At this location the exchange flow has periods with three salinity classes, but 

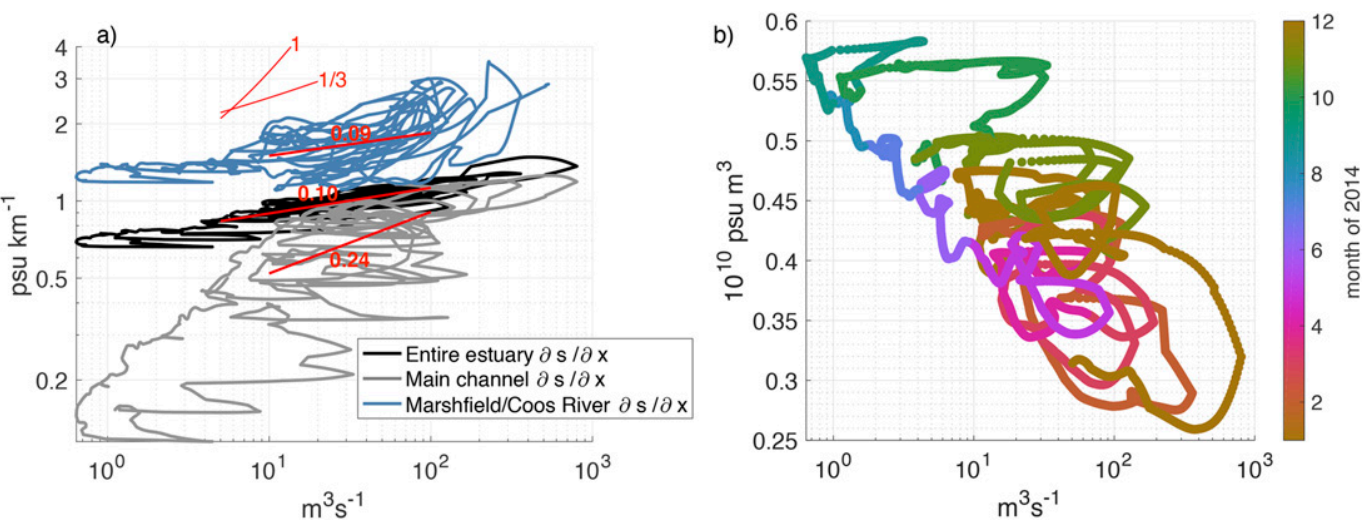

FIG. 8. (a) Relation between $Q_{r}\left(\mathrm{~m}^{3} \mathrm{~s}^{-1}\right)$ and $\partial s / \partial x\left(\mathrm{psu} \mathrm{km}^{-1}\right)$ for the entire study period. The $\partial s / \partial x$ for the entire estuary is colored black and is calculated as the salinity gradient from the mouth to the depth-averaged 2-psu isohaline in Marshfield Channel and the Coos River. Additionally the relation is shown for the segments of the main dredged channel (in gray) and the Marshfield and Coos River channels (in blue). Power-law scalings for each section, and theoretical values of 1 and $1 / 3$ are shown in orange. (b) Relation between $Q_{r}\left(\mathrm{~m}^{3} \mathrm{~s}^{-1}\right)$ and the total salt content $S\left(10^{10} \mathrm{psu} \mathrm{m}^{3}\right)$ of the estuary for the year of 2014, colored by month of 2014 .

also periods with the two classes of saltier inflow and fresher outflow or with two classes with reversed exchange flow (Fig. 10d). Reversed two-class exchange flow occurs during discharge events when pulsing of freshwater from the Coos River creates a reversal of the local along-estuary salinity gradient and freshwater moves into Isthmus Slough, a pattern that persists throughout the wet season.

The TEF method is currently formulated for two salinity classes representing the inflowing and outflowing exchange flow, but it can be extended into more classes based on the integrated $Q(s)$ function (Lorenz et al. 2019). If there are three salinity classes, both the global maximum and minimum of $Q(s)$ should be used as dividing salinities (Fig. 10e), otherwise the transport will be incorrectly classified. For example, two dividing salinities can be found from the $Q(s)$ function (div1 and div2 in Fig. 10e), so that $Q_{\text {in }}$ is the total from the higherand lower-salinity classes and $Q_{\text {out }}$ is the transport in intermediate salinity classes. If the salinity classes vary as in Isthmus Slough, the TEF algorithm must differentiate the exchange flow based on the structure of $Q(s)$.

Here, we bin the exchange flow into three salinity class at the entrance of South Slough (Fig. 10c). The highersalinity inflow $s_{\text {in1 }}$ stays near oceanic values while the inflow at lower-salinity $s_{\text {in } 2}$ varies with discharge from the Coos River. The outflowing $s_{\text {out }}$ is an intermediate salinity, reflecting mixing of the two water masses in the tributary. The volume transport in the higher-salinity class $Q_{\text {in } 1}$ is generally much larger than in the lowersalinity class $Q_{\text {in2 }}$, but they are similar in magnitude during neap tide. The unfiltered $\partial Q / \partial s$ is shown for the entrance to South Slough (Fig. 10f) and Isthmus Slough (Fig. 10g). At the beginning of flood, fresher water in the main channel gets advected into South Slough (Fig. 10f) and during the ebb it is exported as a higher-salinity outflow. Fresher water similarly intrudes into Isthmus Slough during flood (Fig. 10g), yet the transport is more complex than South Slough.

\section{Discussion}

The main results of this study are that in the Coos Estuary, a small estuary with Mediterranean climate forcing, 1) the salt balance is consistently out of equilibrium due to the river discharge and estuary response time scales, 2) the geometry influences the salinity distribution due to bathymetric heterogeneity and multiple connecting tributaries, and 3 ) the salt flux and exchange flow are controlled by tidal processes, in both an Eulerian decomposition and in the TEF framework. These main results are discussed in further detail below, including how the two approaches to the salt flux analysis can be used to quantify the spatial structure of tidal dispersion and temporal variability in total mixing in the estuary.

\section{a. Unsteadiness}

Throughout the study period, $d S / d t$ is a major component of the salt balance (Fig. 7e). The salinity distribution can only be in steady state if the estuary response time is less than the time scale of forcing variability. The freshwater adjustment time is $T_{\mathrm{adj}}=L / 2 u_{O}$ for estuaries where tidal processes dominate (MacCready 2007), where $u_{O}=Q_{R} / a_{0}, a_{0}$ is the average cross-sectional area, and $L$ is the length of the salinity intrusion.

With the exception of the largest discharge events, $T_{\text {adj }}$ in the Coos Estuary is much longer than the duration of 

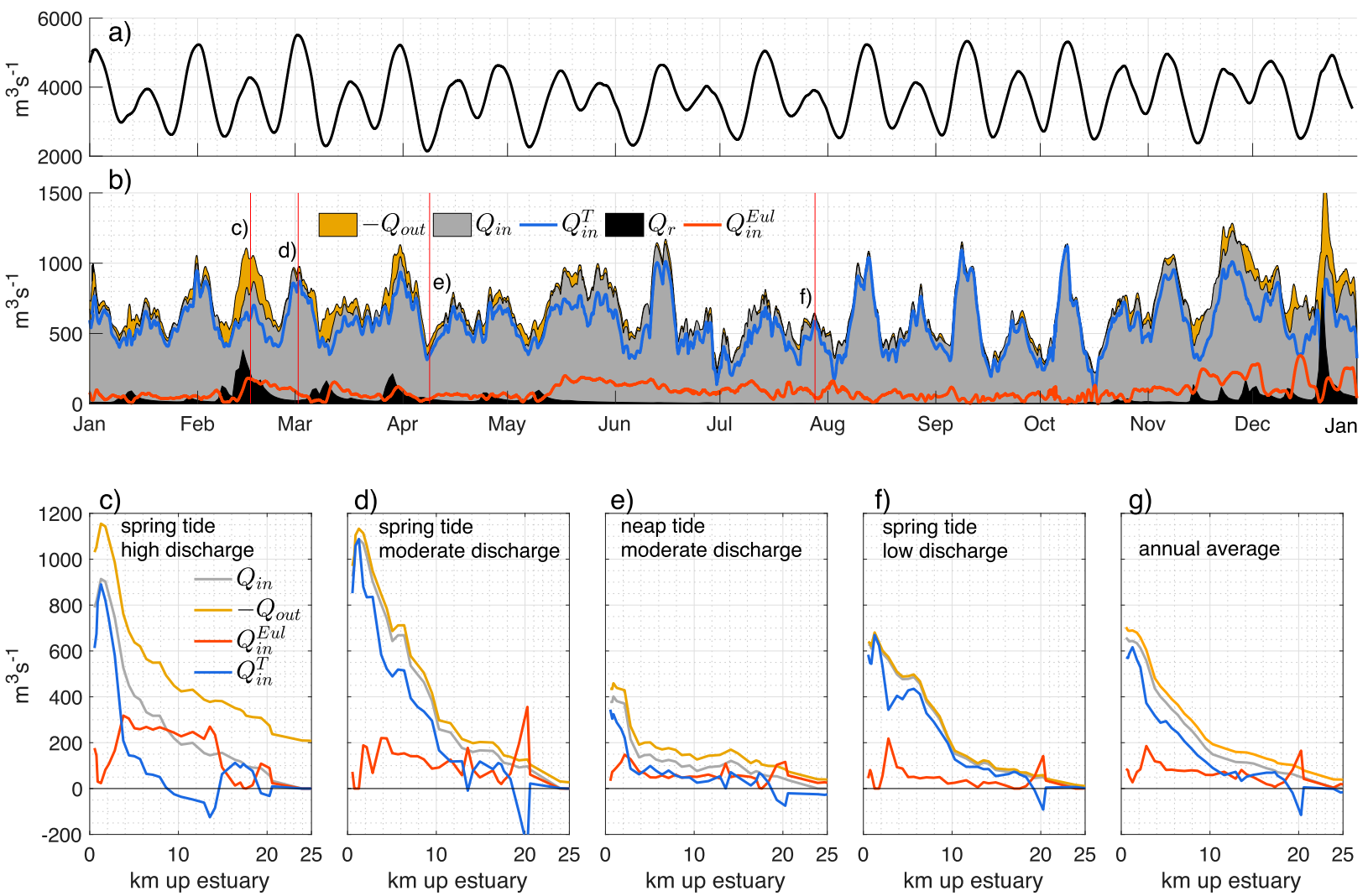

FIG. 9. (a) The tidal volume flux $Q_{\text {tide }}\left(\mathrm{m}^{3} \mathrm{~s}^{-1}\right)$ at the mouth of the estuary over 2014. (b) The TEF fluxes $\left(\mathrm{m}^{3} \mathrm{~s}^{-1}\right)$ at the mouth of the estuary over the year 2014. The outflowing flux $Q_{\text {out }}$ is gold, the inflowing flux $Q_{\text {in }}$ is gray, the inflowing Eulerian flux $Q_{\text {in }}^{\text {Eul }}$ is orange, and the inflowing tidal flux $Q_{\mathrm{in}}^{T}$ is blue. (c)-(f) Snapshots of the along-channel variability are shown, which correspond to the times shown in (b) by vertical lines. (g) The year-long average of the exchange flow terms along the main channel.

discharge events (typically $1-5$ days), so the estuary is unable to equilibrate with its current $Q_{r}$. For example, on March $8 Q_{R} \approx 100 \mathrm{~m}^{3} \mathrm{~s}^{-1}$ and $L \approx 26 \mathrm{~km}$, such that $T_{\text {adj }} \approx 15$ days. During the dry season the adjustment time becomes longer than the summer itself. For example, in August 2014, the discharge of $\sim 1.5 \mathrm{~m}^{3} \mathrm{~s}^{-1}$ corresponds with $T_{\text {adj }} \approx 900$ days. The estuary is thus continuously gaining salt throughout the summer until the first discharge event in the fall. Banas et al. (2004) similarly found that unsteadiness was a major component of the salt balance in Willapa Bay. In the Coos Estuary, the barotropic flux due to sea level variability that becomes part of $F_{r}$ provides an additional major source of unsteadiness in the dry season salt balance, as those fluctuations are also much shorter than the response time.

Unsteadiness as a dominant component of the salinity budget results in a seasonal hysteresis in total salt content with respect to river discharge (Fig. 8b). Similar hysteresis between the salinity structure and discharge was found for Galveston Bay, where it was attributed to long response time scales for the salinity distribution compared to the seasonal forcing (Rayson et al. 2017).
Seasonal hysteresis also occurs for $\partial s / \partial x$, particularly in the main channel of the estuary (Fig. 8a), reducing the usefulness of power law relations between $\partial s / \partial x$ and discharge.

\section{b. Geometrical effects}

The along-channel variability in depth influences the salinity distribution throughout the estuary, as well as the response of $\partial s / \partial x$ to river discharge. If the estuary is separated into the dredged main channel portion (from the mouth to $23 \mathrm{~km}$ ) and the shallower upper estuary including Marshfield Channel and the Coos River, the relationship between $\partial s / \partial x$ and $Q_{r}$ varies along the axis of the estuary (Fig. 8a). The exponent is greater in the main channel $\left(0.24 ; r^{2}=0.62\right)$ than in Marshfield Channel $\left(0.09 ; r^{2}=0.29\right)$, such that the salinity distribution cannot be expressed in a selfsimilar form (e.g., Monismith et al. 2002). Rather than a continuous response to $Q_{r}$ as predicted by theory for uniform estuarine geometry, the salinity field reflects the multiple linked but distinct channel segments and depends more on the bathymetry than river discharge. 

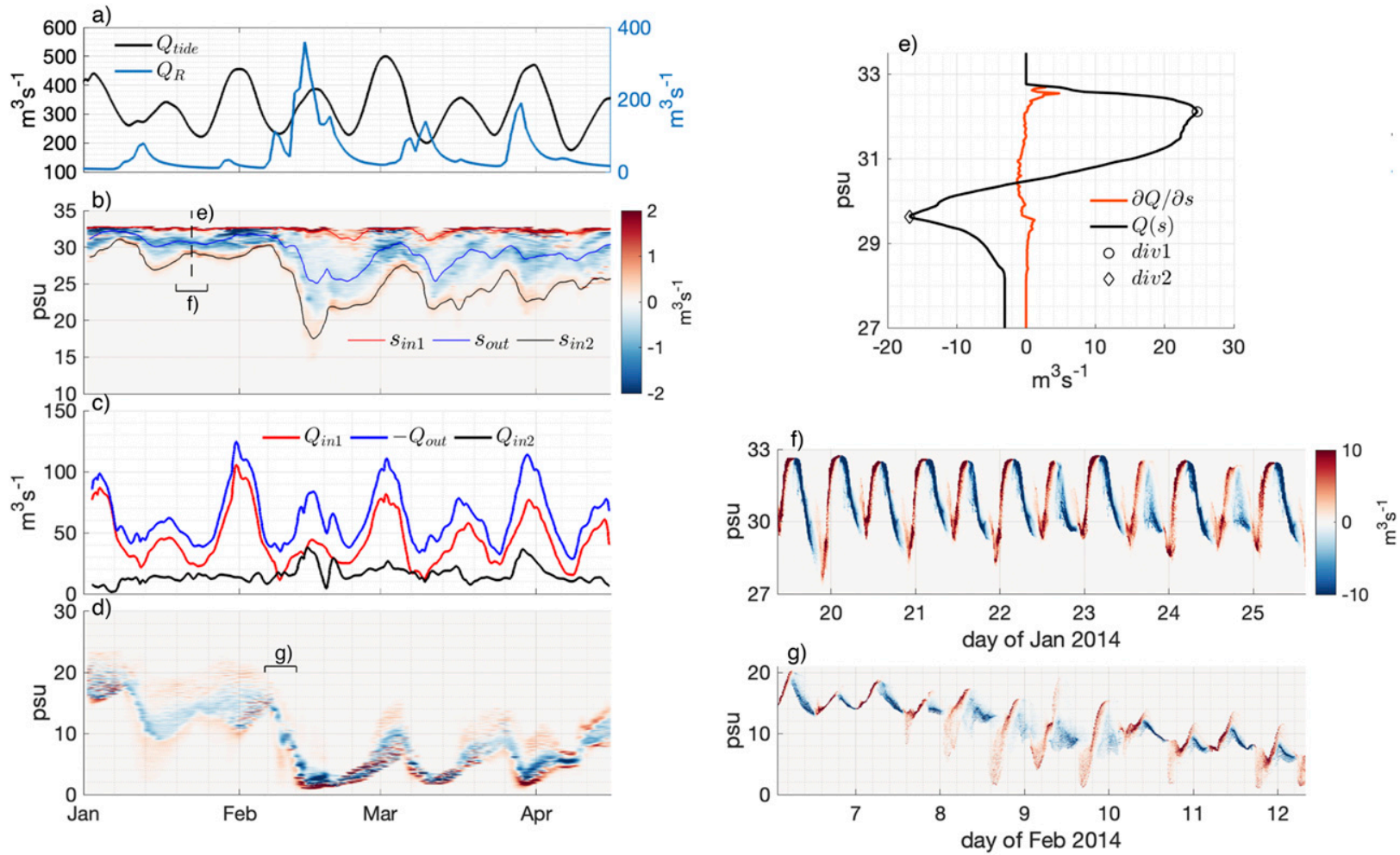

FIG. 10. (a) The $Q_{\text {tide }}\left(\mathrm{m}^{3} \mathrm{~s}^{-1}\right)$ at the entrance to South Slough and $Q_{r}\left(\mathrm{~m}^{3} \mathrm{~s}^{-1}\right)$ from January to April 2014. (b) The $\partial Q / \partial s\left(\mathrm{~m}^{3} \mathrm{~s}^{-1}\right)$ at the entrance to South Slough. The vertical dashed line represents the instance shown in (e), and the bracket corresponds to the period in (f). (c) The TEF volume fluxes $\left(\mathrm{m}^{3} \mathrm{~s}^{-1}\right)$ at the entrance to Sough Slough. (d) The $\partial Q / \partial s\left(\mathrm{~m}^{3} \mathrm{~s}^{-1}\right)$ at the entrance to Isthmus Slough. The color map refers to the color bar in (b). The bracket shown corresponds to the period in (g). (e) The $\partial Q / \partial s\left(\mathrm{~m}^{3} \mathrm{~s}^{-1}\right)$ and $Q(s)\left(\mathrm{m}^{3} \mathrm{~s}-1\right)$ at the dashed line shown in (a). The two dividing salinities are shown as div1 and div2. (f) The $\partial Q / \partial s\left(\mathrm{~m}^{3} \mathrm{~s}^{-1}\right.$; nonfiltered) at the entrance to South Slough for the time period shown in (b). (g) The $\partial Q / \partial s\left(\mathrm{~m}^{3} \mathrm{~s}^{-1}\right.$; nonfiltered) at the entrance to Isthmus Slough for the time period shown in (d). The color map corresponds to the color bar in (f).

Along-channel variability in the partitioning of the exchange flow (e.g., Fig. 9g) is also associated with bathymetric variation along the channel. Two locations where the Eulerian term is relatively large (Fig. 9g) are 3 and $20 \mathrm{~km}$ from the mouth, and correspond to alongchannel changes in cross-sectional geometry. Near $3 \mathrm{~km}$ from the mouth the depth decreases from 20 to $14 \mathrm{~m}$ (Fig. 1c), and near $20 \mathrm{~km}$ the channel widens, increasing the cross-sectional area (Fig. 1d). Although $Q_{\mathrm{in}}^{\mathrm{Eul}}$ and $Q_{\mathrm{in}}^{T}$ vary along the estuary, and at times are negative, $Q_{\text {in }}$ varies with $Q_{\text {tide }}$ and is uniform along the estuary, such that variation in the tidal contribution compensates for the along-channel variability in the Eulerian component. Similar partitioning associated with crosssectional geometry was also found in the Hudson River Estuary (Chen et al. 2012; Wang et al. 2015).

The connecting tributaries show complex water mass transport with the main channel, commonly exhibiting three salinity class (Fig. 10b) or reversed (Fig. 10d) exchange flow. In estuaries where the baroclinic pressure gradient or other subtidal processes drive the exchange flow, reversals in the exchange flow represent a reversal of the vertical structure of the exchange flow (Giddings and MacCready 2017), such that $Q_{\text {in }}$ is fresher and occurs in the upper water column. In the Coos Estuary, the variability in $\partial Q / \partial s$ is related to the tidal variation in transport and the advection of fresher water from the Coos River into the tributaries. The creation of mixed water in tributaries and injection into main channel is similar to tidal trapping mechanisms that are represented as dispersive, up-estuary tidal transport (Okubo 1973; MacVean and Stacey 2011).

\section{c. Mechanisms of tidal dispersion}

The tidal salt flux is typically represented by an alongchannel dispersion coefficient acting on the subtidal salinity gradient. Similarly, a bulk dispersion coefficient based on the average total salt flux due to the combination of subtidal and tidal process can be calculated as $K_{\text {bulk }}=\left(F_{T}+F_{\text {Eul }}\right) /\left(a_{0} \partial s / \partial x\right)$, which is averaged over the year of 2014 and shown along the estuary (Fig. 11). The contribution from the subtidal component is generally 


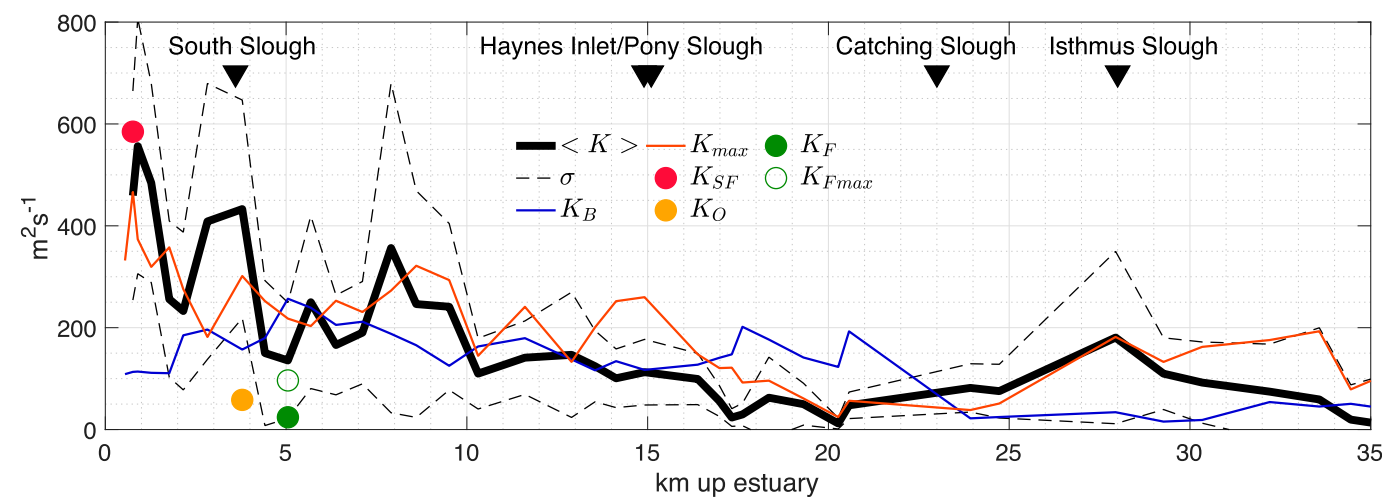

FIG. 11. The mean along-channel dispersion coefficient $K_{\text {bulk }}\left(\mathrm{m}^{2} \mathrm{~s}^{-1}\right)$ in the main channel and into Marshfield Channel and the Coos River, over the entire study period is shown (black), with one standard deviation from the mean shown (black dashed lines). The locations of connecting tributaries are shown by the triangles. Dispersion scalings, including $K_{B}$ (Banas et al. 2004), $K_{\max }$ (Chen et al. 2012), $K_{\mathrm{SF}}$ (Stommel and Farmer 1952), $K_{O}$ (Okubo 1973), and $K_{F}$ (Fischer et al. 1979) are shown at corresponding along-channel locations. Here, $K_{F \max }$ represents lateral shear dispersion when the quantity $\left[\left(1 / T^{\prime}\right) f\left(T^{\prime}\right)\right]$ is maximal.

small, but using the bulk quantity avoids the alongchannel variability from spatial variation in $Q_{\mathrm{in}}^{T}$ and $Q_{\mathrm{in}}^{\mathrm{Eul}}$ (Fig. 9). The temporal variance in $K_{\text {bulk }}$ is primarily due to the spring-neap cycle, as $F_{T}$ and $K_{\text {bulk }}$ increase with tidal amplitude. During the wet season, $K_{\text {bulk }}$ slightly increases.

Near the mouth, $K_{\text {bulk }}$ ranges from 200 to $800 \mathrm{~m}^{2} \mathrm{~s}^{-1}$ and has little seasonal variation. One potential mechanism for tidal dispersion here is jet-sink flow (Stommel and Farmer 1952), which occurs due to asymmetries in velocity and salinity between flood and ebb tide. During ebb, strong velocities near the mouth export mixed, lower-salinity water into the coastal ocean. During flood, oceanic water enters the estuary, most of which was not affected by the previous ebb tide. MacCready (2007) gave an estimate of the dispersion coefficient based on jet-sink flow as

$$
K_{\mathrm{SF}}=\varepsilon \frac{L_{T} u_{T}}{\pi}\left[1-\left(\frac{2 B}{\pi L_{T}}\right)^{1 / 2}\right],
$$

where $u_{T}=Q_{\text {tide }} / a_{0}$ is a representative tidal velocity, $L_{T}=u_{T} T / \pi$ is the tidal excursion, $T$ is the tidal period $\left(\mathrm{M}_{2}\right.$ period used), $B$ is the width $(600 \mathrm{~m})$, and $\varepsilon$ is an empirical constant. MacCready (2007) used $\varepsilon=0.1$ and noted that the value is not well constrained. Using $\varepsilon=1$, and a tidal velocity averaged over the study period, we find good agreement between $K_{\text {bulk }}$ and $K_{\mathrm{SF}}$ of around $600 \mathrm{~m}^{2} \mathrm{~s}^{-1}$ at the mouth.

Other mechanisms shown to cause dispersion include tidal and subtidal eddies (MacCready and Banas 2011), lateral shear dispersion (Fischer et al. 1979) and tidal trapping (Okubo 1973). To represent dispersion associated with tidal eddies, mixing length arguments scale the dispersion coefficient with the estuary width $B$ and the tidal velocity. For example, Banas et al. (2004) found that dispersion in Willapa Bay could be described by $K_{B}=0.35 u_{T} B$. This scaling has the correct magnitude of dispersion when applied to the Coos Estuary, but does not correspond with the along-channel variability (Fig. 11). Lateral shear in the along-channel flow induces dispersion that scales as

$$
K_{F}=0.1 \overline{u^{\prime 2}} T\left[\frac{1}{T^{\prime}} f\left(T^{\prime}\right)\right],
$$

(Fischer et al. 1979) where $u^{\prime}$ is the velocity deviation from the cross-sectional average parameterized as $\overline{u^{\prime 2}=0.2 u_{T}^{2}}$, and $T^{\prime}=T / T_{c}$, where $T_{c}$ is the time for complete lateral mixing $\left(T_{c} \sim B^{2} / 0.6 H u_{T} \sqrt{C_{d}}\right.$ using $\left.C_{d}=0.0025\right)$. Maximum dispersion from lateral processes occurs when the time scale of cross-sectional mixing is similar to half the tidal period, and the quantity $\left[\left(1 / T^{\prime}\right) f\left(T^{\prime}\right)\right]$ reaches a maximum of 0.8 (Fischer et al. 1979). Along the main channel, the average width is $1000 \mathrm{~m}$, and $\left[\left(1 / T^{\prime}\right) f\left(T^{\prime}\right)\right]$ varies from 0.03 to 0.2 , giving dispersion values of $4-24 \mathrm{~m}^{2} \mathrm{~s}^{-1}$. However, using only the width of the dredged main channel $(\sim 100 \mathrm{~m})$ where strong lateral shear occurs (Fig. 6) gives the maximal value of $\left[\left(1 / T^{\prime}\right) f\left(T^{\prime}\right)\right]$ and a dispersion coefficient of $96 \mathrm{~m}^{2} \mathrm{~s}^{-1}$.

Tributaries and side embayments can store salt during the tidal cycle and release it into the main channel during another phase of the tidal cycle, increasing dispersion (Fischer 1976). Okubo (1973) represented this as a dispersion coefficient based on a side embayment that is continuously exchanging with the main channel: 

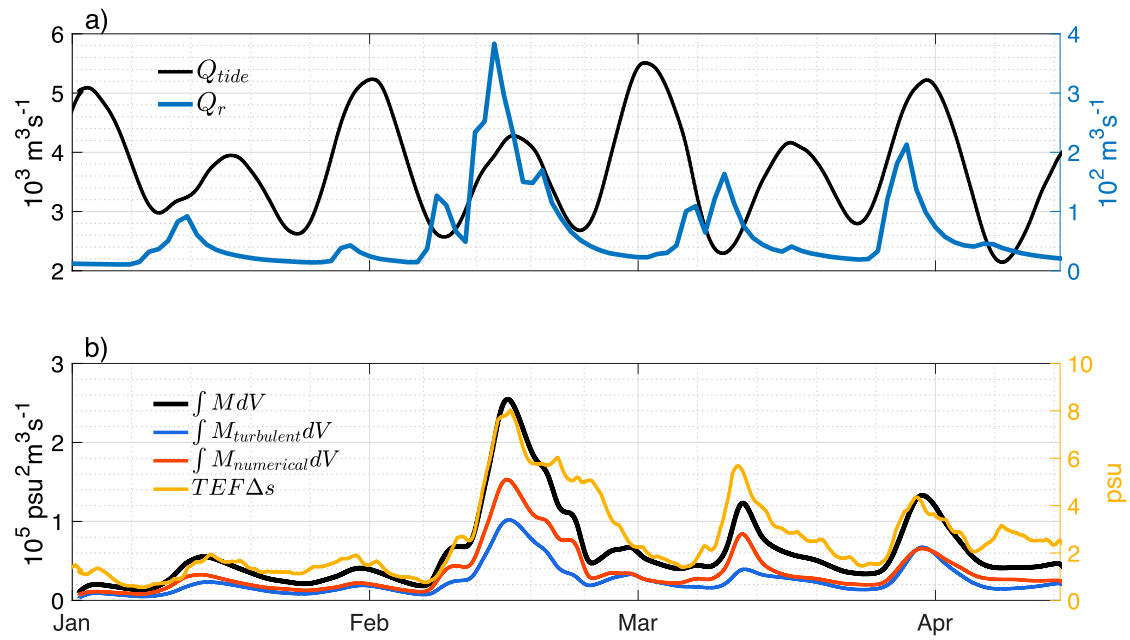

FIG. 12. (a) The tidal volume flux $Q_{\text {tide }}$ in black (left axis) and river discharge $Q_{r}$ in blue (right axis) for January-April 2014. (b) Estuary integrated dissipation of salinity variance (black; left axis), decomposed into the amount calculated by the turbulence closure scheme (blue) and the amount due to numerical mixing (orange). The TEF stratification (psu) at the mouth of the estuary is shown on the right axis in gold.

$$
K_{O}=\frac{K_{\mathrm{bulk}}}{1+r}+\frac{r u_{T}^{2}}{2 t(1+r)^{2}\left(1+r+\frac{\phi}{t}\right)},
$$

where $K_{\text {bulk }}$ is the dispersivity in the main channel, $r$ is the ratio of the tributary volume to channel volume, $t^{-1}$ is the residence time of the tributary, and $\phi=2 \pi / T$. The volume ratio is calculated using the average crosssectional area multiplied by the tidal excursion for the main channel and South Slough, and the residence time is quantified by $\operatorname{TEF}\left(V / Q_{\text {in }}\right)$, which is $1-2$ days for spring and neap tides, respectively. The velocity between the main channel and South Slough are approximately $20^{\circ}$ out of phase, or about $1 / 16$ of the tidal period, and the tidal trapping scaling at this junction gives $60 \mathrm{~m}^{2} \mathrm{~s}^{-1}$. Note that all scaling approaches are sensitive to the velocity scale. For example, if a tidal velocity in the main channel of $1 \mathrm{~m} \mathrm{~s}^{-1}$ is used, rather than the representative tidal velocity $u_{T}$ over the entire cross section $\left(\sim 0.3 \mathrm{~m} \mathrm{~s}^{-1}\right)$, the dispersion coefficient due to tidal trapping would increase to $420 \mathrm{~m}^{2} \mathrm{~s}^{-1}$.

Recognizing that different mechanisms of tidal dispersion have similar scaling terms, Chen et al. (2012) formulated the maximum dispersion associated with tidal processes as $K_{\max }=\alpha u_{T}^{2} T$, where $\alpha$ depends on the dispersive mechanism. This expression is valid for lateral shear dispersion, tidal trapping, and similar processes that contribute to along-estuary dispersion. Using $\alpha=0.05$ as an upper bound (Chen et al. 2012), $K_{\max }$ closely follows $K_{\text {bulk }}$ along the estuary, suggesting that the along-channel variation in tidal velocity is the key factor in the along-channel variability in dispersion. The scaling approaches for a specific mechanism generally fall within the range of $K_{\text {bulk }}$ values, suggesting that multiple processes are contributing to dispersion in the Coos Estuary. It appears that jet-sink flow is important near the mouth, and that lateral processes that scale with the along-channel velocity are important in the interior of the estuary including tidal trapping at tributary junctions. Dispersion coefficients up estuary of a tidal excursion are slightly greater in the wet season, which could be due to a slight increase in gravitational circulation, or increased horizontal salinity gradients resulting in greater dispersion by lateral processes.

\section{d. Relation between the exchange flow and tidal mixing}

The dissipation rate of salinity variance has been used to quantify mixing in estuaries (Wang et al. 2017; Ralston et al. 2017; MacCready et al. 2018), and has clear linkages to exchange flow as quantified by the TEF because mixing is needed to convert inflowing high-salinity water into a lower-salinity class. In numerical models, the dissipation of salinity variance is due to mixing explicitly calculated by the turbulence closure as well as numerical mixing from truncation errors in the salinity advection scheme. The dissipation rate of salinity variance $M$ is expressed in units of $\mathrm{psu}^{2} \mathrm{~s}^{-1}$ and can be viewed as a rate of mixing of salinity. Following Ralston et al. (2017), the total mixing $M$ is the sum of the numerical mixing associated with the advection scheme $M_{\text {numerical }}$ and the turbulent mixing calculated from the turbulence closure $M_{\text {turbulent }}$. 
The estuary integrated mixing $\int M d V$ is shown during the wet season in Fig. 12b, which is decomposed into the contributions from turbulent and numerical mixing. The term $\int M d V$ is strongly related to variation in $Q_{r}$ and subsequently the stratification, with little variability associated with the spring-neap cycle. The contribution from numerical mixing is generally larger than the mixing calculated by the turbulence closure, but the two vary similarly in time. MacCready et al. (2018) derived the steady state relationship between the estuary integrated mixing and the exchange flow as $\int M d V \cong Q_{\text {in }} s_{\text {in }} \Delta s$.

Similar to the Hudson River Estuary (Wang and Geyer 2018), we find that $\int M d V$ and $\Delta s$ are highly sensitive to changes in $Q_{r}$ (Fig. 12b), while $Q_{\mathrm{in}} s_{\text {in }}$ is not and varies instead with $Q_{\text {tide }}$. In the Coos Estuary, the total mixing normalized by the estuarine volume $\left(\int M d V / V\right)$ for the period in Fig. 12 varies between 0.5 and $20 \times 10^{-4} \mathrm{psu}^{2} \mathrm{~s}^{-1}$, while in the Hudson River Estuary $\int M d V / V$ was reported to vary between 0.64 and $5.2 \times 10^{-4} \mathrm{psu}^{2} \mathrm{~s}^{-1}$ over the range of discharge of $Q_{r}=200-2000 \mathrm{~m}^{3} \mathrm{~s}^{-1}$ (Wang and Geyer 2018). The typical discharge in the Coos Estuary is about an order of magnitude less than the Hudson, meaning that for a given $Q_{r}$ the normalized mixing in the Coos Estuary is much greater. Investigating the spatial and tidal variability of $M$ may provide insight to the relationship between $Q_{\text {tide }}$ and $Q_{\text {in }}$.

\section{Conclusions}

A high-resolution model of the Coos Estuary has been developed and evaluated against observations for the year of 2014. The observations and model show large seasonal variation in the salinity distribution associated with the river discharge. Both the Eulerian salt flux decomposition and the total exchange flow (TEF) approach show that the tidal contribution is much larger than the subtidal component. Because of the strong variation in river discharge at both event and seasonal time scales, the estuary rarely approaches equilibrium with forcing conditions and the unsteady term is always a major component of the salt budget. Consequently, typical power-law scaling between the salt structure and river discharge does not describe estuarine conditions well, as a seasonal hysteresis due to the unsteadiness is an essential part of the relationship between the salinity distribution and discharge.

The Coos Estuary is composed of multiple, connected tributary channels, and exchange between them and the main channel is important to the overall salinity dynamics. The TEF framework is adapted to show that the side tributaries import both high-salinity ocean water and relatively low-salinity water from freshwater sources in other parts of the estuary, and export intermediate salinity water due to mixing within the tributary. This division into three distinct salinity classes contrasts the classic import of highersalinity water and export of lower-salinity water, and provides a mechanism for tidal dispersion. The bulk tidal dispersion coefficient scales with the tidal velocity squared, tidal period, and a scaling coefficient $\alpha$ of 0.05 . The scaling is consistent with jet-sink exchange at the mouth, but likely also represents lateral shear dispersion and trapping within side tributaries farther inside the estuary.

In addition to illustrating the exchange of multiple salinity classes at channel junctions, the TEF approach represents the multiple time scales affecting the salinity distribution. The salinity inflow is tidally driven and varies predominantly with the spring-neap cycle, but the outflow, stratification, and mixing, calculated based on the change in salinity variance, are seasonally dependent and vary with the river discharge. This link between the river discharge, stratification, and mixing has been noted in estuaries where subtidal processes (i.e., gravitational circulation) dominate the exchange flow, but it also applies to tidally dominated systems like the Coos Estuary.

Acknowledgments. We thank two anonymous reviewers for constructive comments, the staff of the South Slough National Estuarine Research Reserve for providing time series data, and Parker MacCready for sharing LiveOcean boundary conditions. This work was partially sponsored by the National Estuarine Research Reserve System Science Collaborative, which supports collaborative research that addresses coastal management problems important to the reserves. The Science Collaborative is funded by the National Oceanic and Atmospheric Administration and managed by the University of Michigan Water Center (NAI4NOS4190145). Computations were performed on the University of Oregon high performance computer Talapas.

\section{REFERENCES}

Banas, N. S., B. M. Hickey, P. MacCready, and J. A. Newton, 2004: Dynamics of Willapa Bay, Washington: A highly unsteady, partially mixed estuary. J. Phys. Oceanogr., 34, 2413-2427, https://doi.org/10.1175/JPO2637.1.

Brown, C. A., and R. J. Ozretich, 2009: Coupling between the coastal ocean and Yaquina Bay, Oregon: Importance of oceanic inputs relative to other nitrogen sources. Estuaries Coasts, 32, 219-237, https://doi.org/10.1007/s12237-008-9128-6.

Burchard, H., and Coauthors, 2018: The Knudsen theorem and the total exchange flow analysis framework applied to the Baltic Sea. Prog. Oceanogr., 165, 268-286, https://doi.org/10.1016/ j.pocean.2018.04.004. 
Chen, C., H. Liu, and R. C. Beardsley, 2003: An unstructured grid, finite-volume, three-dimensional, primitive equations ocean model: Application to coastal ocean and estuaries. J. Atmos. Oceanic Technol., 20, 159-186, https://doi.org/10.1175/ 1520-0426(2003)020<0159:AUGFVT>2.0.CO;2.

— R. C. Beardsley, and G. Cowles, 2013: An unstructured grid, finite-volume coastal ocean model: FVCOM user manual. Tech. Rep. SMAST/UMASSD-13-0701, 416 pp.

Chen, S. N., and L. P. Sanford, 2009: Axial wind effects on stratification and longitudinal salt transport in an idealized, partially mixed estuary. J. Phys. Oceanogr., 39, 1905-1920, https://doi.org/10.1175/2009JPO4016.1.

— W. W. Geyer, D. K. Ralston, and J. A. Lerczak, 2012: Estuarine exchange flow quantified with isohaline coordinates: Contrasting long and short estuaries. J. Phys. Oceanogr., 42, 748-763, https:// doi.org/10.1175/JPO-D-11-086.1.

Conroy, T., 2019: The dynamics and exchange flow variability of the Coos Estuary. M.S. thesis, Dept. of Earth Sciences, University of Oregon, $66 \mathrm{pp}$.

Egbert, G. D., and S. Y. Erofeeva, 2002: Efficient inverse modeling of barotropic ocean tides. J. Atmos. Oceanic Technol., 19, 183-204, https://doi.org/10.1175/1520-0426(2002)019<0183: EIMOBO $>2.0 . \mathrm{CO} ; 2$.

Fischer, H. B., 1976: Mixing and dispersion in estuaries. Annu. Rev. Fluid Mech., 8, 107-133, https://doi.org/10.1146/ annurev.fl.08.010176.000543.

— J. E. List, C. R. Koh, J. Imberger, and N. H. Brooks, 1979: Mixing in Inland and Coastal Waters. Academic Press, 483 pp.

Geyer, W. R., and P. MacCready, 2014: The estuarine circulation. Annu. Rev. Fluid Mech., 46, 175-197, https://doi.org/10.1146/ annurev-fluid-010313-141302.

Giddings, S. N., and P. MacCready, 2017: Reverse estuarine circulation due to local and remote wind forcing, enhanced by the presence of along-coast estuaries. J. Geophys. Res. Oceans, 122, $10184-10205$, https://doi.org/10.1002/ 2016JC012479.

_ , and Coauthors, 2014: Hindcasts of potential harmful algal bloom transport pathways on the Pacific Northwest coast. J. Geophys. Res. Oceans, 119, 2439-2461, https://doi.org/ 10.1002/2013JC009622.

Hansen, D. V., and M. Rattray Jr., 1965: Gravitational circulation in straits and estuaries. J. Mar. Res., 23, 104-122.

Hickey, B. M., and N. S. Banas, 2003: Oceanography of the US Pacific Northwest coastal ocean and estuaries with application to coastal ecology. Estuaries, 26, 1010-1031, https://doi.org/ 10.1007/BF02803360.

Hughes, F. W., and M. Rattray Jr., 1980: Salt flux and mixing in the Columbia River estuary. Estuarine Coastal Mar. Sci., 10, 479-493, https://doi.org/10.1016/S0302-3524(80)80070-3.

Largier, J. L., J. T. Hollibaugh, and S. V. Smith, 1997: Seasonally hypersaline estuaries in Mediterranean-climate regions. Estuarine Coastal Shelf Sci., 45, 789-797, https://doi.org/ 10.1006/ecss.1997.0279.

Lerczak, J. A., W. R. Geyer, and R. J. Chant, 2006: Mechanisms driving the time-dependent salt flux in a partially stratified estuary. J. Phys. Oceanogr., 36, 2296-2311, https://doi.org/ 10.1175/JPO2959.1.

Lorenz, M., K. Klingbeil, P. MacCready, and H. Burchard, 2019: Numerical issues of the Total Exchange Flow (TEF) analysis framework for quantifying estuarine circulation. Ocean Sci., 15, 601-614, https://doi.org/10.5194/os-15-601-2019.

MacCready, P., 2007: Estuarine adjustment. J. Phys. Oceanogr., 37, 2133-2145, https://doi.org/10.1175/JPO3082.1.
- 2011: Calculating estuarine exchange flow using isohaline coordinates. J. Phys. Oceanogr., 41, 1116-1124, https://doi.org/ 10.1175/2011JPO4517.1.

—_, and W. R. Geyer, 2010: Advances in estuarine physics. Annu. Rev. Mar. Sci., 2, 35-58, https://doi.org/10.1146/ annurev-marine-120308-081015.

—, and N. S. Banas, 2011: Residual circulation, mixing, and dispersion. Water and Fine Sediment Circulation, E. Wolanski and D. McLusky, Eds., Vol. 2, Treatise on Estuarine and Coastal Science, Elsevier, 75-89.

— W. R. Geyer, and H. Burchard, 2018: Estuarine exchange flow is related to mixing through the salinity variance budget. J. Phys. Oceanogr., 48, 1375-1384, https://doi.org/10.1175/ JPO-D-17-0266.1.

MacVean, L. J., and M. T. Stacey, 2011: Estuarine dispersion from tidal trapping: A new analytical framework. Estuaries Coasts, 34, 45-59, https://doi.org/10.1007/s12237-010-9298-x.

Mazzini, P. L., J. A. Barth, R. K. Shearman, and A. Erofeev, 2014: Buoyancy-driven coastal currents off Oregon during fall and winter. J. Phys. Oceanogr., 44, 2854-2876, https://doi.org/ 10.1175/JPO-D-14-0012.1.

Monismith, S. G., W. Kimmerer, J. R. Burau, and M. T. Stacey, 2002: Structure and flow-induced variability of the subtidal salinity field in northern San Francisco Bay. J. Phys. Oceanogr., 32, 3003-3019, https://doi.org/10.1175/1520-0485(2002)032<3003: $\mathrm{SAFIVO}>2.0 . \mathrm{CO} ; 2$.

Murphy, A. H., 1988: Skill scores based on the mean square error and their relationships to the correlation coefficient. Mon Wea. Rev., 116, 2417-2424, https://doi.org/10.1175/15200493(1988)116<2417:SSBOTM > 2.0.CO;2.

Nidzieko, N. J., and S. G. Monismith, 2013: Contrasting seasonal and fortnightly variations in the circulation of a seasonally inverse estuary, Elkhorn Slough, California. Estuaries Coasts, 36, 1-17, https://doi.org/10.1007/s12237-012-9548-1.

Nunes, R. A., and J. H. Simpson, 1985: Axial convergence in a wellmixed estuary. Estuarine Coastal Shelf Sci., 20, 637-649, https://doi.org/10.1016/0272-7714(85)90112-X.

Okubo, A., 1973: Effect of shoreline irregularities on streamwise dispersion in estuaries and other embayments. Neth. J. Sea Res., 6, 213-224, https://doi.org/10.1016/0077-7579(73) 90014-8.

Pawlowicz, R., B. Beardsley, and S. Lentz, 2002: Classical tidal harmonic analysis including error estimates in MATLAB using T_TIDE. Comput. Geosci., 28, 929-937, https://doi.org/ 10.1016/S0098-3004(02)00013-4.

Pritchard, D. W., 1956: The dynamic structure of a coastal plain estuary. J. Mar. Res., 15, 33-42.

Ralston, D. K., W. R. Geyer, and J. A. Lerczak, 2010: Structure, variability, and salt flux in a strongly forced salt wedge estuary. J. Geophys. Res., 115, C06005, https://doi.org/10.1029/ 2009JC005806.

— - G. W. Cowles, W. R. Geyer, and R. C. Holleman, 2017: Turbulent and numerical mixing in a salt wedge estuary: Dependence on grid resolution, bottom roughness, and turbulence closure. J. Geophys. Res. Oceans, 122, 692-712, https://doi.org/10.1002/2016JC011738.

Rayson, M. D., E. S. Gross, R. D. Hetland, and O. B. Fringer, 2017 Using an isohaline flux analysis to predict the salt content in an unsteady estuary. J. Phys. Oceanogr., 47, 2811-2828, https:// doi.org/10.1175/JPO-D-16-0134.1.

Roegner, G. C., and A. L. Shanks, 2001: Import of coastallyderived chlorophyll-a to South Slough, Oregon. Estuaries, 24, 244-256, https://doi.org/10.2307/1352948. 
__ J. A. Needoba, and A. M. Baptista, 2011: Coastal upwelling supplies oxygen-depleted water to the Columbia River estuary. PLOS ONE, 6, e18672, https://doi.org/10.1371/ journal.pone.0018672.

Ruggiero, P., J. L. Eshleman, E. Kingsley, D. M. Thompson, B. Voigt, G. M. Kaminsky, and G. Gelfenbaum, 2007: Beach morphology monitoring in the Columbia River Littoral Cell: 1997-2005. USGS Data Series 260, 88 pp., https://doi.org/ $10.3133 / \mathrm{ds} 260$

Stommel, H., and H. G. Farmer, 1952: On the nature of estuarine circulation. Woods Hole Oceanographic Institution Tech. Rep. 52-88, 131 pp.

Sutherland, D. A., and M. A. O'Neill, 2016: Hydrographic and dissolved oxygen variability in a seasonal Pacific Northwest estuary. Estuarine Coastal Shelf Sci., 172, 47-59, https:/ doi.org/10.1016/j.ecss.2016.01.042.
Umlauf, L., and H. Burchard, 2003: A generic length-scale equation for geophysical turbulence models. J. Mar. Res., 61, 235-265, https://doi.org/10.1357/002224003322005087.

Wang, T., and W. R. Geyer, 2018: The balance of salinity variance in a partially stratified estuary: Implications for exchange flow, mixing, and stratification. J. Phys. Oceanogr., 48, 2887-2899, https://doi.org/10.1175/JPO-D-18-0032.1.

,$- \ldots$, P. Engel, W. Jiang, and S. Feng, 2015: Mechanisms of tidal oscillatory salt transport in a partially stratified estuary. J. Phys. Oceanogr., 45, 2773-2789, https://doi.org/10.1175/JPO-D-15-0031.1.

, — - and P. MacCready, 2017: Total exchange flow, entrainment, and diffusive salt flux in estuaries. J. Phys. Oceanogr., 47, 1205-1220, https://doi.org/10.1175/JPO-D-16-0258.1.

Warner, J., D. Schoellhamer, J. Burau, and G. Schladow, 2002: Effects of tidal current phase at the junction of two straits. Cont. Shelf Res., 22, 1629-1642, https://doi.org/10.1016/S0278-4343(02)00026-2. 